\title{
Silica-coated magnetic-nanoparticle- induced cytotoxicity is reduced in microglia by glutathione and citrate identified using integrated omics
}

Tae Hwan Shin ${ }^{1}$, Balachandran Manavalan', Da Yeon Lee', Shaherin Basith', Chan Seo ${ }^{2}$, Man Jeong Paik², Sang-Wook Kim³, Haewoon Seo ${ }^{3}$, Ju Yeon Lee ${ }^{4}$, Jin Young Kim, A Young Kim', Jee Min Chung ', Eun Joo Baik1, Seong Ho Kang ${ }^{5,6}$, Dong-Kug Choi ${ }^{7}$, Yup Kang ${ }^{1}$, M. Maral Mouradian ${ }^{8}$ and Gwang Lee ${ }^{9,10^{*}}$ (D)

\begin{abstract}
Background: Nanoparticles have been utilized in brain research and therapeutics, including imaging, diagnosis, and drug delivery, owing to their versatile properties compared to bulk materials. However, exposure to nanoparticles leads to their accumulation in the brain, but drug development to counteract this nanotoxicity remains challenging. To date, concerns have risen about the potential toxicity to the brain associated with nanoparticles exposure via penetration of the brain blood barrier to address this issue.

Methods: Here the effect of silica-coated-magnetic nanoparticles containing the rhodamine B isothiocyanate dye [MNPs@SiO $\left.{ }_{2}(\mathrm{RITC})\right]$ were assessed on microglia through toxicological investigation, including biological analysis and integration of transcriptomics, proteomics, and metabolomics. MNPs@SiO ${ }_{2}(\mathrm{RITC})$-induced biological changes, such as morphology, generation of reactive oxygen species, intracellular accumulation of MNPs@SiO $(\mathrm{RITC})$ using transmission electron microscopy, and glucose uptake efficiency, were analyzed in BV2 murine microglial cells. Each omics data was collected via RNA-sequencing-based transcriptome analysis, liquid chromatography-tandem mass spectrometry-based proteome analysis, and gas chromatography- tandem mass spectrometry-based metabolome analysis. The three omics datasets were integrated and generated as a single network using a machine learning algorithm. Nineteen compounds were screened and predicted their effects on nanotoxicity within the triple-omics network.

Results: Intracellular reactive oxygen species production, an inflammatory response, and morphological activation of

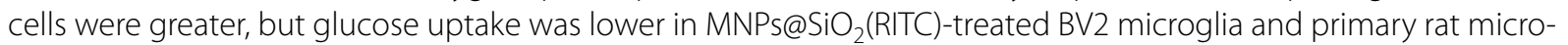
glia in a dose-dependent manner. Expression of 121 genes (from 41,214 identified genes), and levels of 45 proteins (from 5918 identified proteins) and 17 metabolites (from 47 identified metabolites) related to the above phenomena changed in MNPs@SiO 2 (RITC)-treated microglia. A combination of glutathione and citrate attenuated nanotoxicity induced by MNPs@SiO 2 (RITC) and ten other nanoparticles in vitro and in the murine brain, protecting mostly the hippocampus and thalamus.
\end{abstract}

*Correspondence: glee@ajou.ac.kr

${ }^{9}$ Department of Molecular Science and Technology, Ajou University,

Suwon-si, Gyeonggi-do 16499, Republic of Korea

Full list of author information is available at the end of the article

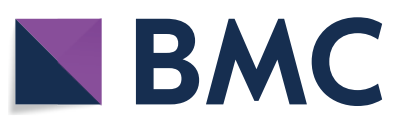

(c) The Author(s) 2021, corrected publication 2021. Open Access This article is licensed under a Creative Commons Attribution 4.0 International License, which permits use, sharing, adaptation, distribution and reproduction in any medium or format, as long as you give appropriate credit to the original author(s) and the source, provide a link to the Creative Commons licence, and indicate if changes were made. The images or other third party material in this article are included in the article's Creative Commons licence, unless indicated otherwise in a credit line to the material. If material is not included in the article's Creative Commons licence and your intended use is not permitted by statutory regulation or exceeds the permitted use, you will need to obtain permission directly from the copyright holder. To view a copy of this licence, visit http://creativecommons.org/licenses/by/4.0/. The Creative Commons Public Domain Dedication waiver (http://creativecommons.org/publicdomain/zero/1.0/) applies to the data made available in this article, unless otherwise stated in a credit line to the data. 
Conclusions: Combination of glutathione and citrate can be one of the candidates for nanotoxicity alleviating drug against MNPs@SiO 2 (RITC) induced detrimental effect, including elevation of intracellular reactive oxygen species level, activation of microglia, and reduction in glucose uptake efficiency. In addition, our findings indicate that an integrated triple omics approach provides useful and sensitive toxicological assessment for nanoparticles and screening of drug for nanotoxicity.

Keywords: Silica-coated magnetic nanoparticles, Nanotoxicity, Integrated omics, Microglia, Machine learning

\section{Graphical Abstract}
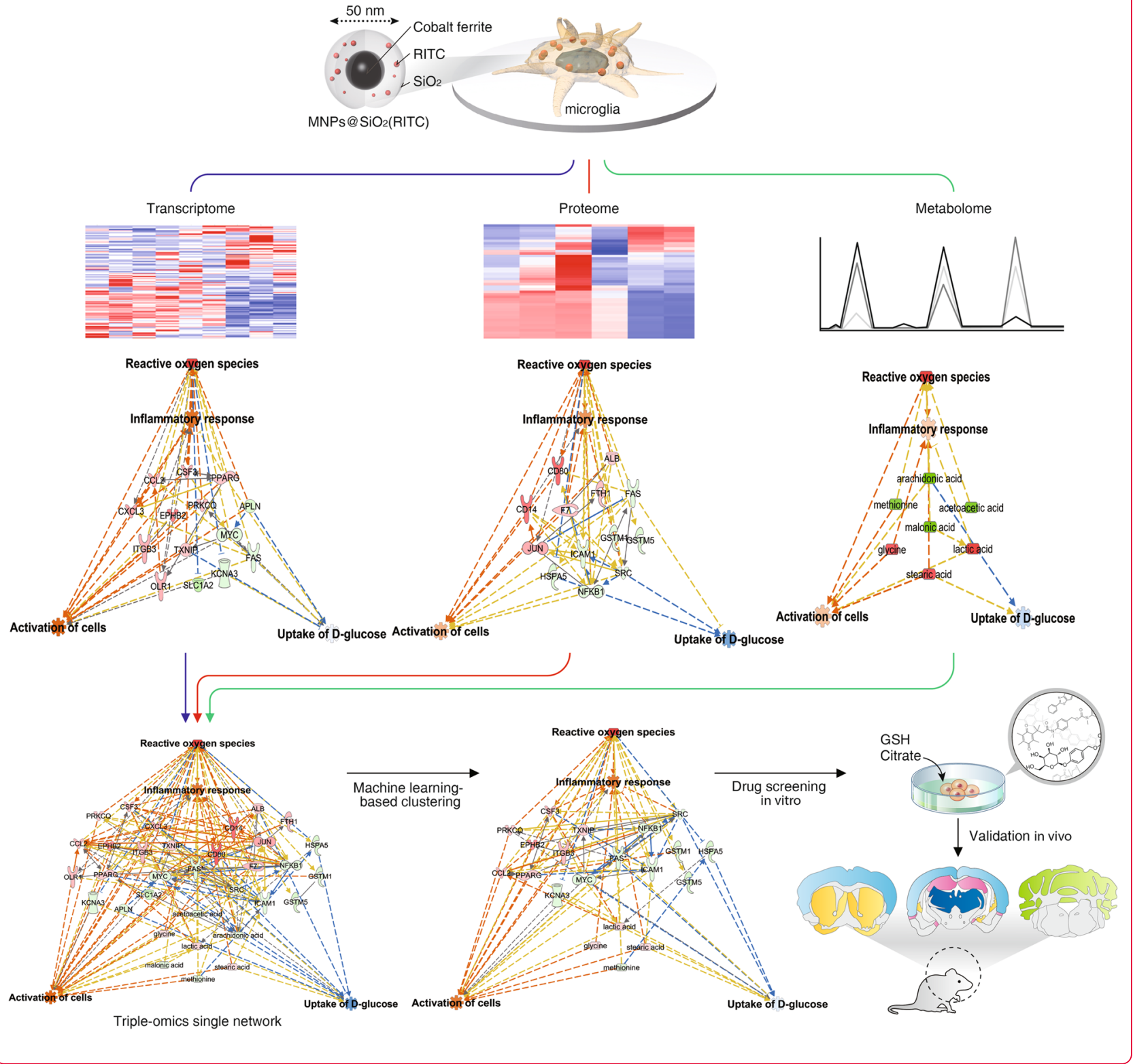

\section{Background}

Broad applications of magnetic nanoparticles (MNPs) and those coated with biocompatible silica and polymers-include contrast agents for magnetic resonance imaging, in vivo tracers, transfection agents, and drug delivery tools [1-5]. Nanoparticles (NPs) have also enabled various technological advances in biotechnology, materials science, engineering, and biomedicine [6-9]. However, there are concerns about their safety owing to the large surface area-to-volume ratio and nanoscale size effects, making them more reactive than bulksized materials [10-12]. Nanomaterial-induced toxicity 
(nanotoxicity) is mostly mediated by redox imbalance, including reactive oxygen species (ROS) production, mitochondrial dysfunction, and energy metabolism dysfunction [13-20]. However, detailed biological evaluations for the mechanisms of the redox imbalance are still limited $[5,21]$. Therefore, an increasing number of studies are focusing on reducing nanotoxicity and identifying the relevant mechanisms [22, 23].

Nanotoxicity to the brain is an increasing concern that is highly related to ROS-induced neurodegeneration [24, $25]$. Some NPs, such as polysorbate $80-\operatorname{coated} \operatorname{poly}(n-$ butyl cyanoacrylate) NPs, MNPs, and silica-coated MNPs containing the rhodamine B isothiocyanate dye [MNPs@ $\mathrm{SiO}_{2}$ (RITC)], penetrate the brain through an active transport mechanism and diffusion without disrupting the blood-brain barrier (BBB) [26-29]. BBB permeability varies by brain region, and the cerebellum, hippocampus, and thalamus are reported to be leakier than other regions due to looser junctional arrangement with differences in junctional protein expression and heterogeneity in distribution of cerebral endothelial cells, pericytes, and astrocytes, of which the BBB is made of [30-32]. Moreover, heterogeneous nanotoxicity and NP accumulation in the brain have been reported $[8,33]$.

Microglia regulate immune homeostasis of the brain and constitute $\sim 5-20 \%$ of the total glial cell population in the central nervous system [34]. They are capable of activation by NPs, and several reports have explained the nature and underlying cellular mechanisms of neuronanotoxicity for microglia in the brain $[33,35,36]$. Activation with concomitant morphological changes, such as assuming a round shape and swelling, are a distinctive property of microglia [37]. Lipopolysaccharide (LPS), an outer membrane component of gram-negative bacteria that activates innate immune cells, is a well-known inducer of microglial activation mainly by binding to toll-like receptor 4 [38]. Peripheral administration and injection of LPS directly into the central nervous system induce immune responses in the brain [39]. Recent studies have shown that intravenously administered LPS induces BBB disruption [40] and $0.025 \%$ of the overall LPS dose entered brain parenchyma in a mouse model [41]. Thus, LPS is often used as positive control for microglial activation in in vitro and in vivo studies $[42,43]$. Moreover, as microglia are one of the major targets for brain-accumulated nanomaterials, their activation induced by nanomaterials can be compared with that promoted by LPS.

Omics analysis involves collective quantification and characterization of an entire set of biomolecules, such as genomics, transcriptomics, proteomics, and metabolomics, which are used in various applications for nanotoxicity evaluation [44-47]. However, a single omics type cannot reveal many complex biological events and interconnected molecular pathways in biological phenomena $[48,49]$. To assess nanotoxicity, integrated omics offers a more comprehensive and precise analysis-as compared to classic methods for nanotoxicity detection or a single-omics analysis-by compensating for the weaknesses in each omics. The present study employed this broad approach with the goal to identify agents that can mitigate nanotoxicity.

\section{Methods}

\section{Nanomaterials}

MNPs@SiO $\mathrm{Si}_{2}$ (RITC) that are comprised of a 9 nm cobalt ferrite $\left(\mathrm{CoFe}_{2} \mathrm{O}_{3}\right)$ core and a RITC-encompassed silica shell [1] were purchased from BITERIALS (Seoul,

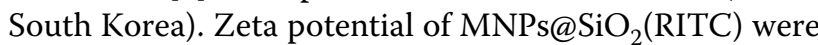
previously reported as -40 to $-30 \mathrm{mV}[1,50]$. X-ray diffraction analysis on a High Power X-Ray Diffractometer (Ultima III, Rigaku, Japan) analyzed the structure of MNPs@SiO 2 (RITC), which showed specific patterns of cobalt ferrite; $(220)$ at $30^{\circ},(311)$ at $36^{\circ},(400)$ at $44^{\circ}$, $(511)$ at $57^{\circ}$, and $(440)$ at $64^{\circ}$. The broad peak between $20^{\circ}$ and $40^{\circ}$ indicated amorphous silica beads [25]. Additionally, we validated whether the non-specific biological effects of MNPs@SiO ${ }_{2}(\mathrm{RITC})$ treatment were induced by the silica shell rather than the $\mathrm{CoFe}_{2} \mathrm{O}_{4}$ core in HEK293 cells because the silica is in the periphery of MNPs@ $\mathrm{SiO}_{2}($ RITC) and directly interacts with biological substances [14, 20, 51, 52]. Ag NPs, Au NPs, and CdSe QDs were generated as in previous studies [53, 54]. In the case of CdSe QDs, the absorption and emission of QDs were analyzed using PDA S-3100 UV/Vis spectrophotometer (Scinco, Korea) and FP-6500 fluorescence spectrometer (Jasco, Japan). Polystyrene micro beads $(2 \mu \mathrm{m}$ and $100 \mathrm{~nm}$ in diameter) and UPM [National Institute of Standards and Technology (NIST)-1648A], were purchased from Sigma-Aldrich. Thirty-nanometre diameter $\mathrm{SiO}_{2} \mathrm{NPs}, \mathrm{TiO}_{2} \mathrm{NPs}$, and MWCNTs were purchased from US Research Nanomaterials.

\section{Isolation and culture of primary microglia and neuronal cells}

Primary rat microglia were isolated from Sprague-Dawley rats (1-day-old). Briefly, rat brains were divided into the cortex and midbrain and homogenized in Minimum Essential Medium (MEM, Gibco, USA). The cell fractions were plated and cultured in a dish containing MEM supplemented with $10 \%$ fetal bovine serum (Gibco, USA), 100 units $/ \mathrm{ml}$ penicillin, and $100 \mathrm{ng} / \mu \mathrm{l}$ streptomycin (Gibco, USA) and incubated in a $5 \%$ humidified $\mathrm{CO}_{2}$ chamber at $37{ }^{\circ} \mathrm{C}$. Primary rat microglia and neuronal cells were separated by the 'shaking off' method [55]. The murine microglial cell line BV2 was chosen as the in vitro model due to its well described nanotoxicological profile $[25,56$, 
57]. These cells were provided by Dr. K. Suk (Kyung-Pook National University, Daegu, Korea) and were cultured under the same conditions as primary rat microglia. Purity of the primary rat microglia was verified by flow-cytometric staining with specific antibodies to OX-42. Neuronal cells were verified by immunocytochemistry with specific antibodies to neuronal nuclei (NeuN) for staining of cortical neurons or antibodies to tyrosine hydroxylase $(\mathrm{TH})$ for visualization of dopaminergic neurons.

\section{Immunoblotting}

For protein samples from in vitro experiments, microglia were seeded at a density of $2 \times 10^{5}$ cells/well in 6-well plates and treated with 0.01 or $0.1 \mu \mathrm{g} / \mu \mathrm{l}$ MNPs@ $\mathrm{SiO}_{2}$ (RITC) for $12 \mathrm{~h}$. Cells were lysed in RIPA buffer (Thermo Fisher Scientific, USA). For protein samples from in vivo experiments, mouse brains were dissected into the cortex, striatum, cerebellum, hippocampus, and thalamus lysed in $10 \%$ Triton X-100 RIPA buffer. Lysates were homogenized, incubated at $4{ }^{\circ} \mathrm{C}$ for $1 \mathrm{~h}$. The samples were centrifuged at $14,000 \mathrm{~g}$ for $15 \mathrm{~min}$ at $4{ }^{\circ} \mathrm{C}$ and supernatants were collected. Protein concentrations in the supernatants were determined with the BCA Kit (Thermo Fisher Scientific, USA). Next, proteins were divided using SDS-PAGE and transferred onto nitrocellulose membranes. The membranes were blocked with $3 \%$ skimmed milk for $1 \mathrm{~h}$ at room temperature and incubated with a primary antibody overnight at $4{ }^{\circ} \mathrm{C}$. The following primary antibodies were used: an anti-Iba1 (1:2000, Novus Biologicals, USA), anti-CD40 (1:2000, Novus Biologicals, USA), anti-CD11b (1:2000, Abcam, USA), and anti- $\beta$ actin (1:5000, Cell Signalling Technology, USA) antibody. Secondary antibodies were used at a dilution of 1:2000 (Santa Cruz Technologies, USA). Enhanced chemiluminescence (ECL, Thermo Scientific, USA) solution was added to the membranes, and luminescence was taken on medical blue X-ray film (AGFA, Belgium) in a dark room.

\section{Evaluation of glucose uptake efficiency and intra/ extra-cellular glucose concentration}

To evaluate the efficiency of glucose uptake, microglia were seeded on a coverslip and treated with 0.01 or $0.1 \mu \mathrm{g} /$ $\mu \mathrm{l} \mathrm{MNPs} @ \mathrm{SiO}_{2}(\mathrm{RITC})$ for $12 \mathrm{~h}$. Cells were then incubated with a fluorescent D-glucose analogue, 2-NBDG, at $37{ }^{\circ} \mathrm{C}$ for $30 \mathrm{~min}$, and the fluorescence images of 2-DG were acquired using fluorescence microscopy (Axio vert $200 \mathrm{M}$, Carl Zeiss, Jena, Germany) at the 3D immune system imaging core facility of Ajou University.

Uptake efficiency of glucose was determined using a luminescence-based kit in accordance with the manufacturer's specifications (Promega, USA). Briefly, microglial cells were treated with 0.01 or $0.1 \mu \mathrm{g} / \mu \mathrm{l}$ MNPs@
$\mathrm{SiO}_{2}(\mathrm{RITC})$ for $12 \mathrm{~h}$. Cells were washed twice with PBS and $1 \mathrm{mM} 2-\mathrm{DG}$ was added. After $10 \mathrm{~min}$, the 2-DG uptake in cells was stopped with an acid detergent solution. $\mathrm{pH}$ was neutralized, and the lysates were mixed with glucose6-phosphate dehydrogenase (G6PDH), nicotinamide adenine dinucleotide phosphate $\left(\mathrm{NADP}^{+}\right)$, ATP, and luciferase. The luminescence was measured using a Synergy 2 luminometer (BioTek, CA), and the images were taken using a ChemiDoc $^{\text {TM }}$ Touch Gel Imaging System (Bio-Rad).

To evaluate intra/extra-cellular glucose, microglia were treated with 0.01 or $0.1 \mu \mathrm{g} / \mu \mathrm{l} \mathrm{MNPs@SiO}{ }_{2}(\mathrm{RITC})$ and subsequently washed twice with PBS. Cell were lysed with an acid detergent solution and neutralized. Lysates were mixed with glucose dehydrogenase, $\mathrm{NADP}^{+}$, ATP, and luciferase. media was 400-fold diluted with PBS for measurement. luminescence was analyzed using a Synergy 2 luminometer (BioTek, CA), and the images were captured using a ChemiDoc ${ }^{\mathrm{TM}}$ Touch Gel Imaging System (Bio-Rad).

\section{Transmission electron microscopy (TEM)}

To analyze the changes in MNPs@SiO 2 (RITC)-treated cells, Karnovsky's fixative solution (Sigma-Aldrich, USA) was used for fixation of MNPs@SiO 2 (RITC)-treated BV2 for $12 \mathrm{~h}$ at $4{ }^{\circ} \mathrm{C}$. Cells were sequentially washed with $0.1 \mathrm{M}$ cacodylate buffer, $\mathrm{pH} 7.4$, and post-fixed with $1 \%(\mathrm{v} / \mathrm{v})$ osmium tetroxide (Polysciences, USA) in a $0.1 \mathrm{M}$ cacodylate buffer for $2 \mathrm{~h}$ at room temperature. Samples were dehydrated with graded ethanol solutions (50-100\%), infiltrated with propylene oxide, and embedded in Epon Mixture (Polysciences, USA). Samples were incubated at $35^{\circ} \mathrm{C}$ for $6 \mathrm{~h}$, at $45^{\circ} \mathrm{C}$ for $12 \mathrm{~h}$, and at $60{ }^{\circ} \mathrm{C}$ for $24 \mathrm{~h}$. Blocks were sectioned with an ultramicrotome (Reichert-Jung, Bayreuth, Germany). Sections were double-stained with $6 \%$ uranyl acetate for 20 min (EMS, USA) and lead citrate for $10 \mathrm{~min}$ (Thermo Fisher Scientific, USA) for contrast staining. Images were acquired via a SIGMA500 (Zeiss, Germany) transmission electron microscope at the 3D immune system imaging core facility of Ajou University. Particle number, vesicle size, mitochondrial number and size were analyzed using Zen blue 2.3 image analysis module (Zeiss, Germany).

\section{Proteome sample preparation}

BV2 cells were treated with 0.01 and $0.1 \mu \mathrm{g} / \mu \mathrm{l}$ MNPs@ $\mathrm{SiO}_{2}(\mathrm{RITC})$ for $12 \mathrm{~h}$. Cells were lysed with RIPA buffer. Lysates were cleared by centrifugation, and the samples were denatured with $8 \mathrm{M}$ urea and reduced with $5 \mathrm{mM}$ tris(2-carboxyethyl) phosphine at room temperature for 10 and $60 \mathrm{~min}$. Samples were alkylated with $15 \mathrm{mM}$ iodoacetamide in the dark for $60 \mathrm{~min}$ at RT, and the buffer was replaced with $200 \mathrm{mM}$ triethylammonium bicarbonate buffer. The total amount of proteins was measured by the Qubit Assay (Thermo Fisher Scientific, USA) following the 
manufacturer's protocol. Three biological replicate samples

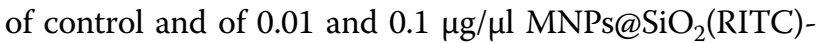
treated groups were pooled as the respective groups. Proteins were digested with trypsin at $37^{\circ} \mathrm{C}$ for $16 \mathrm{~h}$ (Promega, USA). Total peptide concentration was re-quantified by the Qubit Assay (Thermo Fisher Scientific, USA) following the manufacturer's protocol. Each sample of $100 \mu \mathrm{g}$ was divided into two fractions. Samples were individually labelled using TMT-126 and 127 (Control), TMT-128 and -129 [0.01 $\mu \mathrm{g} / \mu \mathrm{l} \mathrm{MNPs} @ \mathrm{SiO}_{2}$ (RITC)-treated group], and TMT-130 and -131 [0.1 $\mu \mathrm{g} / \mu \mathrm{l}$ MNPs@SiO ${ }_{2}(\mathrm{RITC})$-treated group] following the manufacturer's protocol. An aqueous hydroxylamine solution $(5 \% \mathrm{w} / \mathrm{v})$ was used for quenching the reaction. The six TMT-labelled samples were then combined, speed-vacuum dried, and then resuspended in $30 \mu \mathrm{l}$ of water for fractionation by high-pH reversed-phase liquid chromatography [58].

\section{Liquid chromatography with tandem mass spectrometry (LC-MS/MS) analysis for proteome samples}

TMT-labeled peptides were quantified using an Easy nLC 1200 (Thermo Fisher scientific, USA) combined with an Orbitrap Fusion Lumos mass spectrometer (Thermo Fisher Scientific, USA), and a nano-electrospray source (Thermo Fisher Scientific, USA) [59]. Before separation, Peptides were trapped with a $75 \mu \mathrm{m} \times 2 \mathrm{~cm} \mathrm{C} \mathrm{C}_{18}$ precolumn (Thermo Fisher Scientific, USA). analytical $\mathrm{C}_{18}$ column $(75 \mu \mathrm{m} \times 50 \mathrm{~cm}$, Thermo Fisher Scientific, USA) was used and the flow rate was $300 \mathrm{nl} / \mathrm{min}$. Zero to eighty $\%$ acetonitrile containing $0.1 \%$ formic acid was used as mobile phases $A$ and $B$, respectively. The mobile phase gradient was used $6 \%$ phase $B$ for 1 min and was elevated to $25 \%$ phase B for $75 \mathrm{~min}$, to $40 \%$ phase B for $15 \mathrm{~min}$, to $100 \%$ phase $B$ for $1 \mathrm{~min}$, and maintained at $100 \%$ phase $B$ for $8 \mathrm{~min}$, and $2 \%$ phase $\mathrm{B}$ for additional $5 \mathrm{~min}$. The column was maintained with $2 \%$ phase B for $15 \mathrm{~min}$. The $1900 \mathrm{~V}$ voltage was used to generate an electrospray. For chromatographic separation, the mass spectrometer was conducted in data-dependent mode and automatically $3 \mathrm{~s}$ cycle time switching between MS1 and MS2.

\section{Gas chromatography with MS/MS (GC-MS/MS)}

GC-MS/MS analysis was conducted on a gas chromatograph (Shimadzu 2010 Plus, Shimadzu, Kyoto, Japan) combined with a triple quadruple mass spectrometer (Shimadzu TQ 8040, Shimadzu, Kyoto, Japan). A crosslinked capillary column (Ultra-2, 95\% methylpolysiloxane-and $5 \%$ phenyl-bonded phase; $25 \mathrm{~m} \times 0.20 \mathrm{~mm}$ inner diameter, $0.11 \mu \mathrm{m}$ film thickness, Agilent Technologies, Atlanta, GA, USA) were used for separation. Samples were added in split-injection mode (10:1). The operation temperature was $\left(60^{\circ} \mathrm{C}\right.$ for $2 \mathrm{~min}$, elevated to $255^{\circ} \mathrm{C}$ at a rate of $25^{\circ} \mathrm{C} / \mathrm{min}$, elevated to $300^{\circ} \mathrm{C}$ at a rate of $7{ }^{\circ} \mathrm{C} / \mathrm{min}$, with a holding $2.5 \mathrm{~min}$ ). The temperatures were $260{ }^{\circ} \mathrm{C}$ for the injector, $300{ }^{\circ} \mathrm{C}$ for interface, and $230{ }^{\circ} \mathrm{C}$ for ion source were, respectively. Carrier (helium) and collision (argon) gases were used and the electron ionization (EI) mode was adjusted to $70 \mathrm{eV}$.

\section{Unsupervised principal component analysis (PCA)}

To evaluate the relevance and to trim the triple-omics network (transcriptomics, proteomics, and metabolomics), we performed PCA. Each value in each omics was normalized to Z-scores, so that the data were on a similar scale of changed levels for clustering analysis. The multidimensional Z-score of each gene, protein, and metabolite was transformed into a two-dimensional space, where the first-dimension (PC1) and second dimension (PC2) are linear combinations of original values with a certain weight [60]. To identify the largest cluster in the PCA plot, we applied the unsupervised K-means clustering algorithm implemented in Scikit, a machine learning tool in Python [61]. This method takes two-dimensional data (from PCA) and tries to group them into ' $K$ ': number of clusters, where $\mathrm{K}$ is user defined. The pseudo code for the $\mathrm{K}$-means algorithm was as follows:

Input: $k$ (the number of clusters)

D (set of data points without class labels to be clustered)

Output: Clusters $C=\left\{C_{1}, C_{2}, \ldots, C_{\mathrm{k}-1}, C_{\mathrm{k}}\right\}$

while termination is not satisfied do:

foreach instance $D_{\mathrm{p}}$ do:

Calculate the distance of $D_{\mathrm{p}}$ to each cluster centroid.

Assign $D_{\mathrm{p}}$ to the closest centroid.

Update centroids by averaging instances within each cluster.

To test the robustness of the clusters, we also tested the unsupervised $k$-nearest neighbour $(k-\mathrm{NN})$ algorithm (instead of $k$-means clustering) implemented in Scikit with default parameters $(k=3$, algorithm $=$ 'ball_tree'), where $\mathrm{k}$ is the number of neighbours, and the algorithm is the choice of neighbours' search. Of note, we obtained a result similar to the one above, indicating its robustness regardless of the algorithm.

\section{Evaluation of microglial activation in vivo}

This work has received approval for research ethics from Laboratory Animal Research Center of Ajou University Medical Center and proof/certificate of approval is available upon request. All animal experiments were conducted in accordance with experimental protocols 
approved by the Laboratory Animal Research Center of Ajou University Medical Center (approval no. 20200033). The design of the animal study is reported previously $[25,26]$. Mice (male ICR, 8 weeks old, Orientbio, Seongnam, Korea) were maintained on a $12 \mathrm{~h}$ light/dark cycle with free access to food and water. Four mice per group were used in this study. Another study analyzed the biodistribution and the toxicological impact of MNPs@ $\mathrm{SiO}_{2}(\mathrm{RITC})$ at doses of 25,50 , and $100 \mathrm{mg} / \mathrm{kg}$ [26]. The study uncovered a broad tissue distribution of MNPs@ $\mathrm{SiO}_{2}$ (RITC) and brain localization of MNPs@SiO ${ }_{2}(\mathrm{RITC})$ without $\mathrm{BBB}$ disruption. Moreover, there were no significant adverse manifestations, such as growth, aberrant behaviours, biochemical changes in serum, or histopathology, even at the $100 \mathrm{mg} / \mathrm{kg}$ dose. However, based on our in vitro observations, we postulated that there will be subtle toxicity in the brain at the $100 \mathrm{mg} / \mathrm{kg}$ dose, which is the maximum concentration in the previous study [26]. Thus, $\mathrm{MNPs@SiO}$ (RITC) were injected intraperitoneally in sterile saline at a dose of $100 \mathrm{mg} / \mathrm{kg}$ per mouse. GSH and citrate (Sigma-Aldrich, USA) were dissolved in sterile saline, and $\mathrm{pH}$ levels were adjusted to 7.4. A mixture of GSH and citrate was injected intraperitoneally at doses of $1000 \mathrm{mg} / \mathrm{kg}$ and $200 \mathrm{mg} / \mathrm{kg}$, respectively. Control mice were injected with sterile saline only. The endpoint for analysis was set to 5 days according to a previous biodistribution study [26]. Five days after injection, mice were anaesthetized with urethane $(1.2-1.5 \mathrm{~g} / \mathrm{kg}$, intraperitoneally), the hearts were rapidly exposed, and the mice were perfused transcardially with paraformaldehyde (PFA). The brains were fixed in PFA for $24 \mathrm{~h}$. Brains were submerged in $30 \%$ sucrose and then sectioned at $5 \mu \mathrm{m}$ and stored at $-80^{\circ} \mathrm{C}$ until further analysis.

Fixed, frozen sections were blocked in a $1 \%$ bovine serum albumin (Sigma-Aldrich, USA) with 10\% donkey serum (Sigma-Aldrich, USA) in PBS at room temperature for $2 \mathrm{~h}$. Tissue sections were stained with a polyclonal goat anti-Ibal antibody (1:100, Novus biologicals, USA) diluted in $1 \%$ donkey serum in PBS with $0.4 \%$ Triton $\mathrm{X}-100$ and incubated at $4{ }^{\circ} \mathrm{C}$ overnight. The sections were rinsed and washed ( 3 times for $10 \mathrm{~min}$ ) in PBS with $0.4 \%$ Triton X-100. A secondary antibody was a Thermo Scientific Alexa Fluor 488-conjugated donkey anti-goat IgG antibody at 1:100 dilution in 1\% donkey serum in PBS with $0.4 \%$ Triton X-100 and was incubated for $2 \mathrm{~h}$ at room temperature. The samples were mounted with the Vectashield mounting medium containing DAPI (Vector Laboratories) and coverslips were applied. Immunostained sections were scanned with slide scanner (Axio Scan.Z1, Zeiss, Germany) at the 3D immune system imaging core facility of Ajou University, and regions of interest were viewed via a $40 \times$ objective lens under an A1R HD25 confocal microscope (Nikon, Japan) at the 3D immune system imaging core facility of Ajou University. Three-dimensional reconstructions of branch structures were conducted, and their numbers and lengths were determined using Imaris 9.2 software (Bitplane, Zurich, Switzerland).

\section{Statistical analysis}

The results were subjected to one-way analysis of variance (ANOVA) and Tukey's honestly significant difference (HSD) post hoc test in the IBM-SPSS software (IBM Corp., USA). Differences were considered statistically significant at $p<0.05$.

\section{Results}

\section{Characterization of nanoparticles}

The nanoparticles used in this study were characterized using TEM, X-ray diffraction analysis, and UV/ Vis and fluorescence spectrometry. As determined by TEM, the MNPs@SiO $\mathrm{Si}_{2}$ (RITC) and $\mathrm{SiO}_{2} \mathrm{NPs}$ were found to be $50 \mathrm{~nm}$ in diameter (Additional file 1: Fig. S1). Dose-dependent effects on cell viability were analyzed in the BV2 cell line and primary rat microglia with 0-1.0 $\mu \mathrm{g} / \mu \mathrm{l}$ MNPs@SiO ${ }_{2}(\mathrm{RITC})$ and $1.0 \mu \mathrm{g} / \mu \mathrm{l} \mathrm{MNPs} @$ $\mathrm{SiO}_{2}$ (RITC) treatment for $12 \mathrm{~h}$, which reduced viability by approximately $80 \%$ in both cell types (Additional file 1: Fig. S2). Ag and Au NPs, and CdSe QDs were characterized regarding their uniformity and size using TEM (Additional file 1: Fig. S3). In the case of CdSe QDs, the absorption and emission of the QDs were also analyzed (Additional file 1: Fig. S4).

\section{Phenotypic characterization of MNPs@SiO ${ }_{2}$ (RITC)-treated microglia in vitro}

The efficiency of MNPs@SiO ${ }_{2}$ (RITC) uptake was higher in BV2 cells and rat primary microglia than in primary cortical and dopaminergic neurons (Additional file 1: Fig. S5), when any of these cells were treated with 0.01 or $0.1 \mu \mathrm{g} / \mu \mathrm{l} \mathrm{MNPs}_{\mathrm{SiO}}(\mathrm{RITC})$ for $12 \mathrm{~h}$ (Additional file 1: Fig. S6). The differences were more pronounced with $0.01 \mu \mathrm{g} / \mu \mathrm{l}$ MNPs@SiO ${ }_{2}(\mathrm{RITC})$ treatment. Moreover, the uptake rate reached a plateau in $0.1 \mu \mathrm{g} / \mu \mathrm{l}$ MNPs@ $\mathrm{SiO}_{2}(\mathrm{RITC})$-treated BV2 cells and primary microglia, and viability decreased by $\sim 80 \%$ among $1.0 \mu \mathrm{g} / \mu \mathrm{l}$ MNPs@ $\mathrm{SiO}_{2}(\mathrm{RITC})$-treated BV2 cells and primary microglia after $12 \mathrm{~h}$ (Additional file 1: Fig. S2). Therefore, the dose chosen to treat microglia with MNPs@SiO $($ RITC) in this study ranged from 0.01 to $0.1 \mu \mathrm{g} / \mu \mathrm{l}$. Intracellular ROS level increased after $0.1 \mu \mathrm{g} / \mu \mathrm{l} \mathrm{MNPs@SiO}{ }_{2}$ (RITC) treatment compared to no-treatment control and $0.01 \mu \mathrm{g} / \mu \mathrm{l}$ MNPs@SiO ${ }_{2}(\mathrm{RITC})-$ treated cells (Additional file 1: Fig. S7).

Various signs of morphological activation of microglia, including swelling and rounding, were monitored for $12 \mathrm{~h}$ 
after LPS or MNPs@SiO ${ }_{2}$ (RITC) treatment (Fig. 1a, b). The morphological characteristics of BV2 cells and primary microglia changed after MNPs@SiO ${ }_{2}$ (RITC) or LPS treatment dose-dependently (Fig. 1c). Moreover, expression level of microglial activation markers, including OX-6, Iba1, and CD40, also increased in a dose-dependent manner (Fig. 1d, e). A 1000-fold higher concentration of MNPs@SiO ${ }_{2}$ (RITC) than LPS was necessary to trigger microglial activation, and the magnitude of response to MNPs@SiO ${ }_{2}(\mathrm{RITC})$ was similar in BV2 cells and primary microglia.

Subsequently, we assessed the effect of 10 other types of nanomaterials (at doses 0.01 and $0.1 \mu \mathrm{g} / \mu \mathrm{l}$ for $12 \mathrm{~h}$ ), that are produced from widespread minerals and used in daily life, e.g. $50 \mathrm{~nm}$ silica $\mathrm{NPs}\left(\mathrm{SiO}_{2} \mathrm{NPs}\right), 20 \mathrm{~nm}$ silver NPs (Ag NPs), $15 \mathrm{~nm}$ gold NPs (Au NPs), cadmium selenide quantum dots (CdSe QDs), $2 \mu \mathrm{m}$ and $100 \mathrm{~nm}$ polystyrene particles (PSs), $40 \mathrm{~nm}$ titanium dioxide NPs $\left(\mathrm{TiO}_{2} \mathrm{NPs}\right), 30 \mathrm{~nm} \mathrm{SiO}_{2} \mathrm{NPs}$, urban particulate matter (UPM), and $25 \mathrm{~nm}$ outer diameter (OD) multi-walled carbon nanotubes (MWCNTs), on morphological activation and death of microglia (Additional file 1: Fig. S8). Using $50 \mathrm{~nm} \mathrm{SiO}_{2} \mathrm{NPs}$ [same chemical composition and size as the MNPs@SiO 2 (RITC) shell], Ag NPs, Au NPs, and CdSe QDs, resulted in the morphological activation of microglia. Two $\mu \mathrm{m}$ and $100 \mathrm{~nm}$ PSs and $\mathrm{TiO}_{2}$ NPs caused cell death and were accumulated over cells. Thirty $\mathrm{nm} \mathrm{SiO}_{2}$ NPs, UPM, and MWCNTs also induced cell death. In particular, the biological effects on micro-

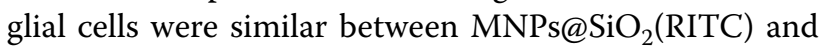
$50 \mathrm{~nm} \mathrm{SiO}{ }_{2}$ NPs.

A significant decrease in glucose uptake was observed in MNPs@SiO $\mathrm{SITC}_{2}$ (RIT)-treated BV2 cells and primary microglia using fluorescent-based analysis, when compared with untreated control cells, and this effect was concentration dependent (Fig. 1f, g). Evaluation of glucose uptake using enzyme-based analysis also showed a similar trend (Fig. 1h). Moreover, the amount of intracellular glucose was significantly lower in MNPs@ $\mathrm{SiO}_{2}$ (RITC)-treated BV2 cells (Fig. 1i), whereas extracellular glucose showed a reverse pattern (Fig. 1j).
To assess changes in cellular organelles after MNPs@ $\mathrm{SiO}_{2}$ (RITC) treatment, we visualized the ultrastructure of BV2 cells by TEM. The distribution of MNPs@ $\mathrm{SiO}_{2}($ RITC) was clearly visible as black dots, and changes in mitochondrial size and number were most pronounced among all cellular organelles at the $0.1 \mu \mathrm{g} / \mu \mathrm{l}$ concentration of the MNPs@SiO $\mathrm{S}_{2}$ (RITC) (Fig. 1k). The number of MNPs@SiO ${ }_{2}($ RITC) per unit cell area was determined, and there was $\mathrm{a} \sim 14$-fold difference between 0.01 and $0.1 \mu \mathrm{g} / \mu \mathrm{l} \mathrm{MNPs@SiO}{ }_{2}(\mathrm{RITC})-$ treated BV2 cells (Fig. 1l).

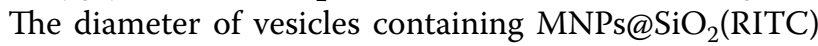
was $\sim 800 \mathrm{~nm}$ (Fig. $1 \mathrm{~m}$ ). The number of mitochondria increased $\sim$ fourfold (Fig. $1 \mathrm{n}$ ), and the cross-sectional area of each mitochondrion decreased by $75 \%$ in $0.1 \mu \mathrm{g} / \mu \mathrm{l}$ MNPs@SiO 2 (RITC)-treated BV2 cells compared to notreatment control (Fig. 1o). Phenotypically, reduced glucose uptake with increased ROS, inflammatory response, activation of cells, and mitochondrial fission were noted in MNPs@SiO ${ }_{2}$ (RITC)-treated microglia.

\section{Transcriptome, proteome, and metabolome analyses of MNPs@SiO 2 (RITC)-treated BV2 cells}

We investigated the transcriptome of BV2 cells by highthroughput RNA sequencing (RNA-seq) after $12 \mathrm{~h}$

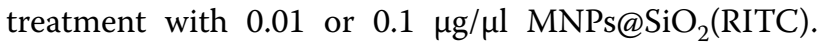
Higher concentration of MNPs@SiO ${ }_{2}$ (RITC) $(1.0 \mu \mathrm{g} /$ $\mu \mathrm{l})$ resulted in severe cell death and could not be used for omics analyses. We identified 41,214 genes and 4760 genes were differentially expressed (fold change $\geq 1.5$ and $\leq-1.5$ ). Among the genes, we select the most significantly changed gene cluster for analysis. Upon the comparison of $0.01 \mu \mathrm{g} / \mu \mathrm{l} \mathrm{MNPs} @ \mathrm{SiO}_{2}(\mathrm{RITC})$-treated cells to no-treatment control cells, 31 genes were found to be, and differentially expressed 121 genes were identified in $0.1 \mu \mathrm{g} / \mu \mathrm{l} \mathrm{MNPs@SiO}{ }_{2}(\mathrm{RITC})$-treated cells in the gene cluster (Fig. 2a). Moreover, Gene Ontology analyses revealed that these genes were highly related to a stress response, signal transduction, and transport, among other cellular functions (Fig. 2b). Next, we analyzed the transcriptomic network of the 121 genes by Ingenuity Pathway Analysis (IPA, http://www.ingenuity.com) in

\footnotetext{
(See figure on next page.)

Fig. 1 Phenotype of MNPs@SiO 2 (RITC)-treated microglial cells. Morphological analysis of a BV2 cells and $\mathbf{b}$ primary rat microglia. Scale bar=50 $\mu \mathrm{m}$. Red: MNPs@SiO 2 (RITC). LPS treatment served as a positive control for activation of microglia. c Quantification of swelled and rounded (activated) microglia compared to ramified microglia. $\mathbf{d}$ Flow-cytometric analysis of BV2 cells and primary microglia for activation marker, OX-6. e Immunoblotting analysis for microglia activation markers, Iba1 and CD40. $\beta$-actin served as an internal control. Visual analysis of glucose uptake efficiency was performed on 2-[N-(7-nitrobenz-2-oxa-1,3-diazol-4-yl)amino]-2-deoxy-D-glucose (2-NBDG)-treated BV2 cells $\mathbf{f}$ and primary microglia g. Scale bar $=20 \mu \mathrm{m}$. Analysis of glucose uptake efficiency with 2-deoxy-D-glucose (2-DG) $\mathbf{h}$ and glucose amounts in MNPs@SiO, (RITC)-treated cells $\mathbf{i}$ and media $\mathbf{j}$ were determined from the luminescent images. $\mathbf{k}$ Representative images of MNPs@SiO $2(\mathrm{RITC})$-treated BV2 cells. Magnified images

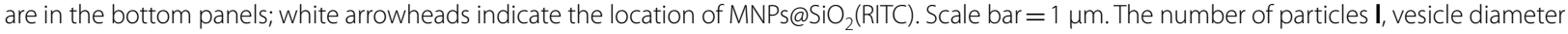
$\mathbf{m}$, number of mitochondria $\mathbf{n}$, and mitochondrial size $\mathbf{o}$ were determined. Data represent the means \pm standard deviation of three independent experiments. ${ }^{*} p<0.05$ versus control, ${ }^{\#} p<0.05$ versus $0.01 \mu \mathrm{g} / \mu \mathrm{MNPs} @ \mathrm{MSO}_{2}(\mathrm{RITC})$-treated cells
} 
A
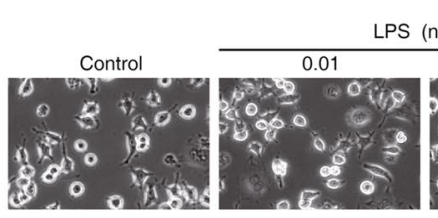

S $(n g / \mu l)$
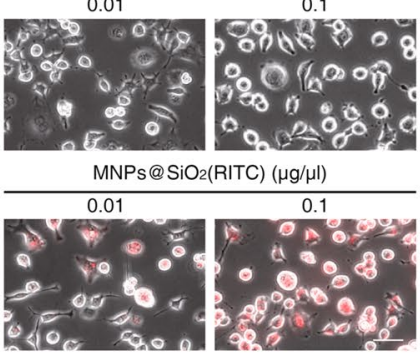

C

$\square$ Control
$\square$ LPS, $0.01 \mathrm{ng} / \mu \mathrm{l} \square \mathrm{MNPs} @ \mathrm{SiO}_{2}(\mathrm{RITC}), 0.01 \mu \mathrm{g} / \mu \mathrm{l}$ LPS, $0.1 \mathrm{ng} / \mu \mathrm{l} \backsim \mathrm{MNPs} @ \mathrm{SiO}_{2}(\mathrm{RITC}), 0.1 \mu \mathrm{g} / \mu \mathrm{l}$

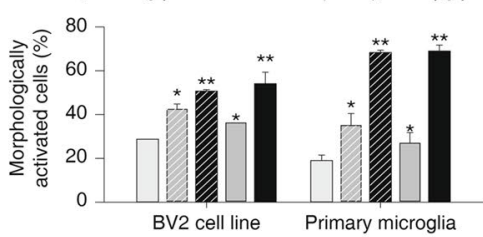

$\mathrm{F}$

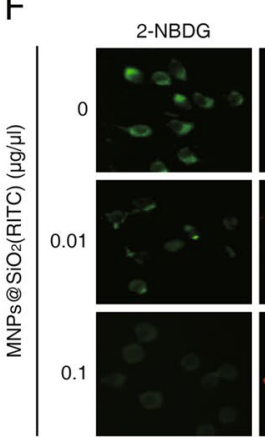

MNPs@SiO

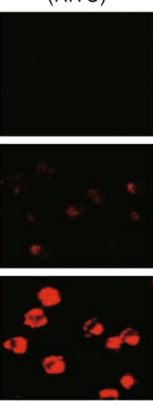

$\mathrm{H}$

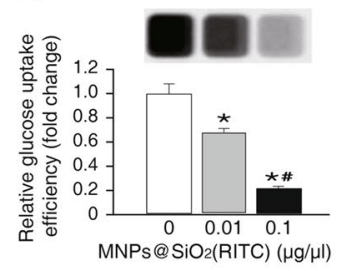

K

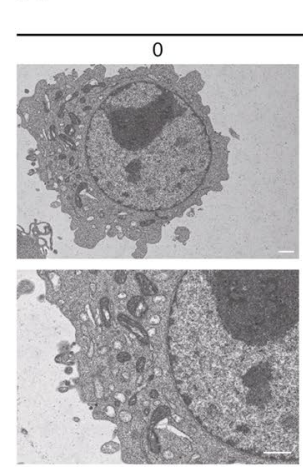

MNPs@ $\mathrm{SiO}_{2}(\mathrm{RITC})(\mu \mathrm{g} / \mathrm{\mu l})$
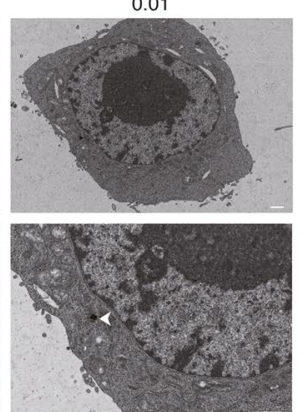

S $0.01 \mathrm{ng} / \mu \mathrm{l}$-MNPs@SiO2(RITC), $0.01 \mu \mathrm{g} / \mu \mathrm{l}$

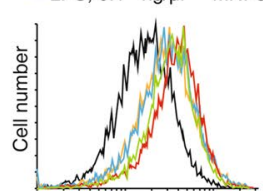

BV2 cell line
B

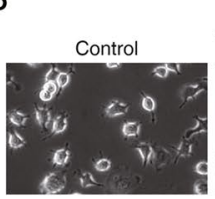

S (ng/ $/$ l)
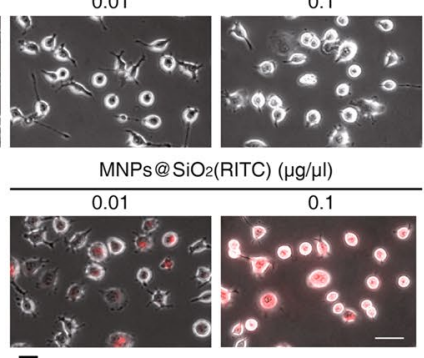

E

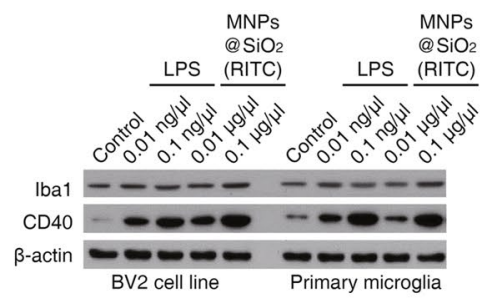

MNPs@SiO
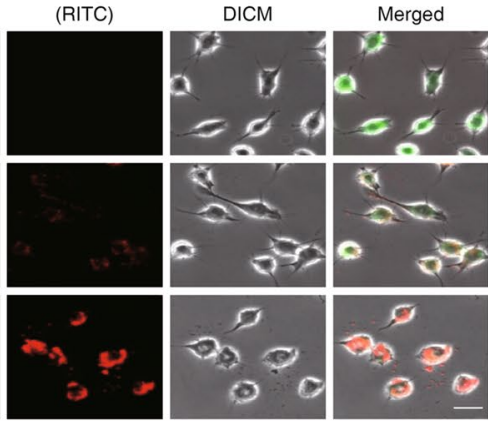

$J$

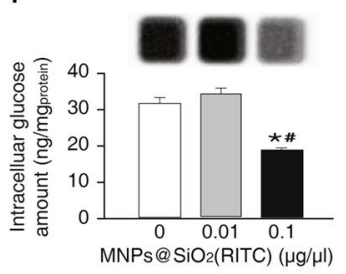

$\mathrm{L}$

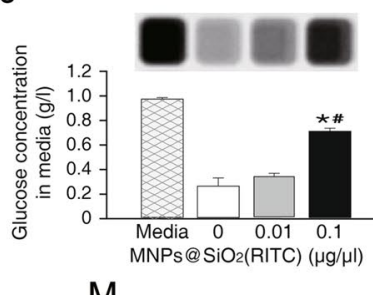

$\mathrm{M}$

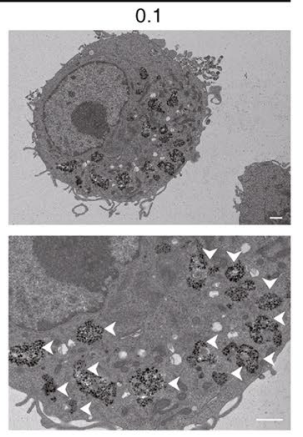

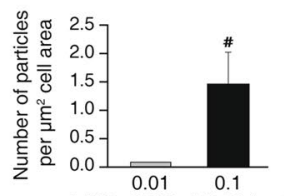

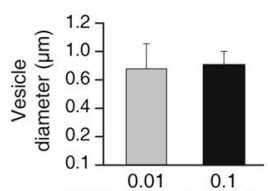

$\mathrm{N}$

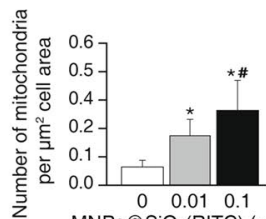
MNPs@SiO2(RITC) $(\mu \mathrm{g} / \mu \mathrm{l})$
$\mathrm{O}$

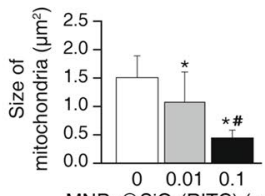

MNPs@SiOz(RITC) $(\mu \mathrm{g} / \mu \mathrm{I})$

Fig. 1 (See legend on previous page.) 
0.01 or $0.1 \mu \mathrm{g} / \mu \mathrm{l} \mathrm{MNPs} @ \mathrm{SiO}_{2}(\mathrm{RITC})$-treated BV2 cells. This analysis showed that these genes were related to four biological functions, including ROS, inflammatory response, activation of cells, and D-glucose uptake (Additional file 1: Figs. S9 and S10 and Table S1), which were useful for predicting biological functions (Additional file 1: Figs. S11 and S12). Furthermore, canonical pathways and biological functions related to the genes were investigated (Additional file 1: Tables S2 and S3). The transcriptome network was trimmed by providing higher relevance to the biological functions (Additional file 1: Fig. S13), and the prediction of the network uncovered up-regulation of ROS, an inflammatory response, and activation of cells with a decrease in D-glucose uptake (Fig. 2c and Additional file 1: Fig. S14). Among the genes in the network, Txnip, Itgb3, Olr1, Pparg, Prkcq, Fas, Apln, Myc, Kcna3, and Slc1a2 were analyzed by quantitative PCR (qPCR) and tended to be up- or downregulated, similar to what was seen in the IPA network (Fig. 2d).

The proteome changes in MNPs@SiO $\mathrm{Si}_{2}(\mathrm{RITC})$-treated BV2 cells were investigated by LC-MS/MS. We identified 5,918 proteins and 482 proteins were differentially expressed (fold change $\geq 1.5$ and $\leq-1.5$ ). Among the proteins, we select the most significantly changed protein expression cluster for analysis. When $0.01 \mu \mathrm{g} / \mu \mathrm{l}$ MNPs@ $\mathrm{SiO}_{2}$ (RITC)-treated cells were compared to untreated controls, 27 proteins were found to be differentially expressed and differentially expressed 45 proteins were identified in $0.1 \mu \mathrm{g} / \mu \mathrm{l} \mathrm{MNPs@SiO}{ }_{2}(\mathrm{RITC})-$ treated cells in the protein expression cluster (Fig. 2e). Gene Ontology analysis revealed that these proteins were related to the stress response and signal transduction (Fig. 2f). Moreover, the proteome network showed that these proteins were highly associated with the same four biological functions identified from the transcriptomic network analysis (Additional file 1: Figs. S15 and S16 and Table S4) and were useful for in silico predictions (Additional file 1: Figs. S17 and S18). Canonical pathways and biological functions were also analyzed among the proteins
(Additional file 1: Tables S5 and S6). The proteome network was trimmed by providing higher relevance to the four biological functions (Additional file 1: Fig. S19), and the prediction of the network uncovered up-regulation of the same four functions, like increased ROS, inflammatory response, activation of cells, and down-regulation of D-glucose uptake (Fig. 2g and Additional file 1: Fig. S20). Among the proteins in the network, the relative abundance levels of Fas, Gstm1, Gstm5, Icam1, Nfkb1, and Src tended to be up- or down-regulated, similar to what was observed in the network analysis (Fig. 2h).

We then performed profiling of 13 fatty acids (FAs), 20 amino acids (AAs), and 14 organic acids (OAs) in 0.01 or $0.1 \mu \mathrm{g} / \mu \mathrm{l}$ MNPs@SiO${ }_{2}$ (RITC)-treated BV2 cells via ethoxycarbonyl (EOC)/methoxime (MO)/tert-butyldimethylsilyl (TBDMS) derivatization and GC-MS/MS analyses (Additional file 1: Table S7). A visual star symbol plot was built using the metabolite composition values of FAs, AAs, and OAs, based on Additional file 1: Table S8 (Fig. 3a). Among the metabolites with altered levels (fold change $\geq 1.2$ and $\leq-1.2$ ), decreased levels of three FAs, two AAs, and seven OAs, and increased levels of two FAs, two AAs, and one OA were noted in $0.1 \mu \mathrm{g} / \mu \mathrm{l}$ MNPs@SiO ${ }_{2}(\mathrm{RITC})$-treated BV2 cells. Similarly, decreased levels of three FAs, four AAs, and seven OAs, and increased levels of three AAs and one OA were

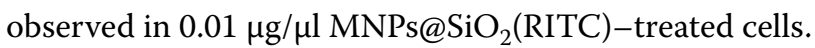

Metabolic profiles were then studied to generate a metabolomic network via IPA (Fig. 3b and Additional file 1: Fig. S21) and to predict up- or down-regulation for the four biological functions (Additional file 1: Fig. S22). Canonical pathways and biological functions were analyzed in relation to the metabolites (Additional file 1: Tables S9 and S10). The network was trimmed by requiring higher relevance to the four biological functions (Additional file 1: Fig. S23), and the network prediction revealed again up-regulation of ROS, an inflammatory response, activation of cells, and down-regulation of D-glucose uptake in 0.1 and $0.01 \mu \mathrm{g} / \mu \mathrm{l}$ MNPs@ $\mathrm{SiO}_{2}(\mathrm{RITC})$-treated BV2 cells (Fig. 3c and Additional

(See figure on next page.)

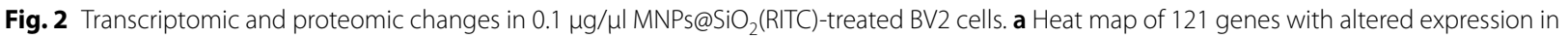

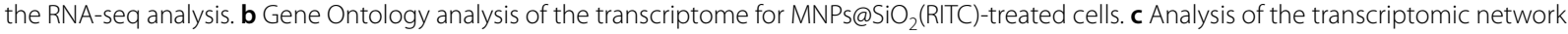
with prediction using IPA in MNPs@SiO 2 (RITC)-treated BV2 cells. The analysis involved a fold change cut-off value \pm 1.5 . Red and green nodes indicate genes that were up-regulated and down-regulated, respectively, compared to the control. Orange and blue arrows indicate prediction of activation and inhibition, respectively. Details for shape and color, which are originated from Ingenuity Systems (http://www.ingenuity.com), are provided in Figs. S9 and S11. d qPCR analysis was performed to determine gene expression in each group, with GAPDH as an internal control. Data represent means \pm standard deviation of three independent experiments. ${ }^{*} p<0.05$ versus control and ${ }^{\#} p<0.05$ versus $0.01 \mu \mathrm{g} / \mu \mathrm{l}$ MNPs@ $\mathrm{SiO}_{2}$ (RITC)-treated cells. e Heat map of 45 proteins with altered expression in LC-MS/MS analysis. $\mathbf{f}$ Gene Ontology analysis of the proteome for MNPs@SiO ${ }_{2}$ (RITC)-treated cells. $\mathbf{g}$ Functional analysis of the proteomic network with prediction using IPA in MNPs@SiO $\mathrm{M}_{2}(\mathrm{RITC})$-treated cells. The analysis used a fold-change cut-off value $\geq \pm 1.5$. Details for shape and color are provided in Figs. S9 and S11. $\mathbf{h}$ The relative abundance levels of Fas, Gstm1, Gstm5, Icam1, Nfkb1, and Src according to LC-MS/MS analysis. Data represent means \pm standard deviation of the two TMT ratios. ${ }^{*} p<0.05$ versus control 


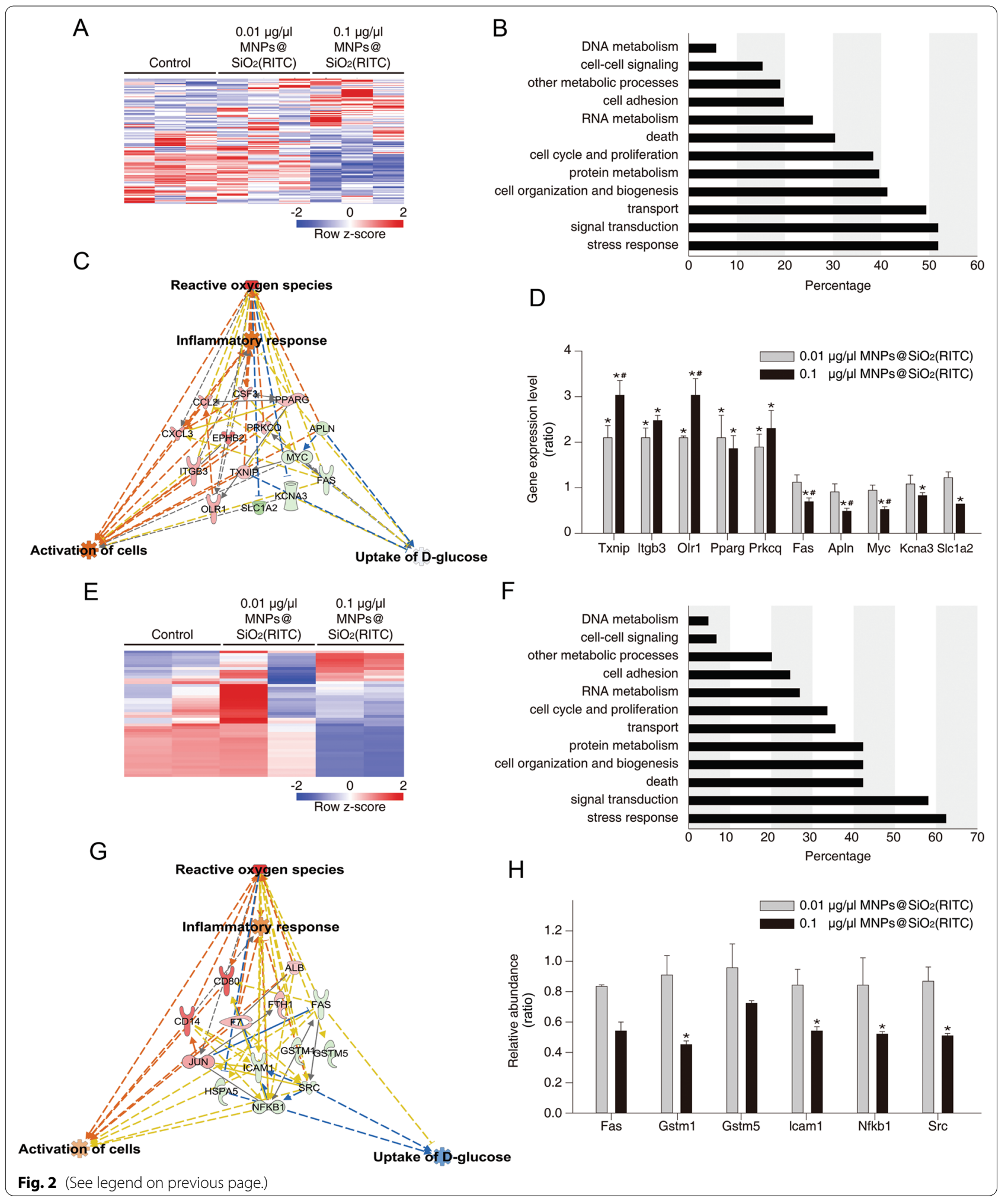

file 1: Fig. S24). Representative selected-ion monitoring chromatograms of stearic acid, glycine, methionine, and lactic acid in the metabolomic network are presented in Fig. 3d. 


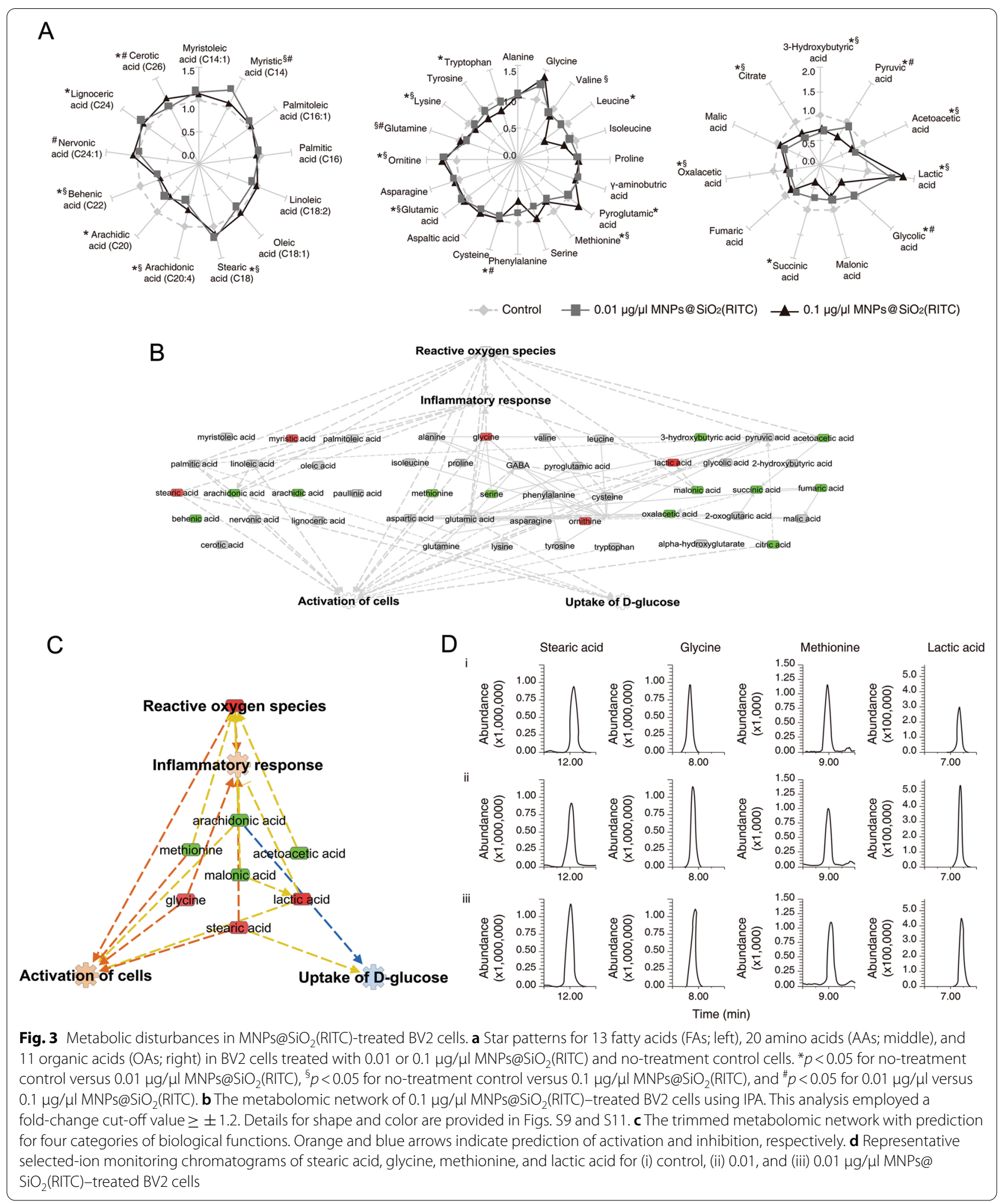




\section{Integrated analysis of the triple-omics network} and screening for drugs that alleviate nanotoxicity

To compensate for potential weaknesses of each omics, we combined three omics studied above to create a triple-omics network (Additional file 1: Fig. S25) [62-65]. The predictions about four biological functions were consistent with those of the aforementioned single-omics network predictions (Fig. 4a and Additional file 1: Fig. S26). The integrated triple-omics related factors (genes, proteins, and metabolites) and four biological functions (i.e. ROS, inflammatory response, activation of cells, and D-glucose uptake) were subjected to machine learning-based unsupervised analysis using the $k$-NN algorithm. The overall integrated triple-omics biplot, where each data point represents individual omics factor, each involved in one of the four biological functions, is depicted in Fig. 4b. When we carried out the calculations for each group [control, 0.01, and $0.1 \mu \mathrm{g} / \mu \mathrm{l}$ MNPs@ $\mathrm{SiO}_{2}(\mathrm{RITC})$ treated BV2 cells], such a relation was not observed (Additional file 1: Fig. S27). According to the data distribution, we identified three clusters, one major and two minor ones. Of note, most factors congregated within one major dominant cluster, thus, indicating their stronger relations despite the observed functional differences. To further elucidate the cross-talk points among these triple-omics data and to generate an integrated network, we re-selected genes, proteins, and metabolites in the major cluster in Fig. 4b (indicated by filled circles), constructed an IPA network (Additional file 1: Fig. S28), and carried out a prediction of the trimmed network (Fig. 4c and Additional file 1: Fig. S29). The trimmed integrated networks based on biological functions showed strong relations between the factors and biological functions.

To find drugs that can alleviate nanotoxicity, i.e. to screen 19 drugs with three major categories of agents: those affecting calcium signalling, tricarboxylic acid (TCA) cycle, and stress signaling [66], we added each drug to the network, and the antioxidant glutathione (GSH) was found to be the most effective towards the triple-omics network and related to each factor (Fig. 4d and Additional file 1: Fig. S30). To validate the effect of GSH and to screen other drugs, BV2 cells were treated with $0.1 \mu \mathrm{g} / \mu \mathrm{l} \mathrm{MNPs} @ \mathrm{SiO}_{2}$ (RITC) for $24 \mathrm{~h}$ along with one of the three major categories of agents (Fig. 4e). The viability of MNPs@SiO $2($ RITC)-treated BV2 cells was $\sim 50 \%$ lower compared to control cells. Rotenone, citrate, sodium salicylate, L-NG-monomethyl-L-arginine (NMMA), $N$-acetyl cysteine (NAC), and GSH alleviated nanomaterial-induced cell death, whereas dichloroacetate and chelerythrine reduced cell viability.

In the metabolome profile, we found predominant down-regulation of OAs-except for lactic acid-in MNPs@SiO 2 (RITC)-treated BV2 cells. We examined selected-ion monitoring chromatograms for 10 detected OAs (except for lactic acid, Additional file 1: Fig. S31). The canonical pathway network for the TCA cycle was examined (Additional file 1: Fig. S32), and a prediction of the network showed a reduction in ATP levels followed by down-regulation of OAs (Additional file 1: Fig. S33). In contrast, addition of citrate to the prediction network triggered up-regulation of ATP (Additional file 1: Fig. S34). Thus, we postulated that supplementation of OAs with citrate might alleviate the decrease in energy metabolism caused by MNPs@SiO $2(\mathrm{RITC})$ treatment. We chose citrate and GSH for further study because of their nanotoxicity-alleviating activity, biocompatibility, and natural origin.

\section{Evaluation of protective effects of GSH and citrate against nanotoxicity in vitro and in vivos}

We incubated primary microglia with MNPs@ $\mathrm{SiO}_{2}$ (RITC) for $24 \mathrm{~h}$ in the presence of each drug or both drugs, and levels of intracellular ATP were evaluated. ATP concentration decreased by $50 \%$ in $0.1 \mu \mathrm{g} /$

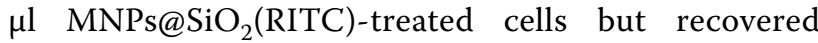

\footnotetext{
(See figure on next page.)

Fig. 4 Creation of a triple-omics integrated network in MNPs@SiO 2 (RITC)-treated BV2 cells. a The simply merged triple-omics network of 0.1 $\mu$ g/ IMNPs@SiO 2 (RITC)-treated BV2 cells. Left group: transcriptome, Right group: proteome, Bottom group: metabolome. Down-regulated Fas was shared between the transcriptome and proteome in center. b PCA for triple omics against four categories of biological functions. Filled spots indicate items included in the simply merged triple-omics network. The translucent yellow circle indicates the location of the major dominant cluster. c The trimmed integrated network for four categories of biological functions. $\mathbf{d}$ The trimmed triple-omics network with addition of GSH. Factors directly related to GSH are highlighted in magenta. e Evaluation of viability in $0.1 \mu \mathrm{g} / \mu \mathrm{MNPs@SiO} \mathrm{MNIT}_{2}$ (RITreated BV2 cells co-treated with each of 19 drugs. AICAR: AMP-activated protein kinase activator; GW3965: nonsteroidal liver X receptor agonist; Nif: nifedipine, calcium channel blocker; Nim: nimodipine, voltage-dependent calcium channel blocker; A23187: calcium ionophore; dantrolene: calcium ion release inhibitor; DCA: dichloroacetate, pyruvate dehydrogenase activator; Rotenone: inhibitor of electron transport chain; citrate: a supplement for TCA cycle; SB216763: glycogen synthase kinase 3 inhibitor; Bay7082: inhibitor of inhibitory KB kinase; sodium salicylate: an NFKB inhibitor; SP: SP600125, C-JUN N-terminal kinase inhibitor; NMMA: L-NG-monomethyl-L-arginine, iNOS inhibitor; Che: chelerythrine, pan-protein kinase C inhibitor; apocynin: inhibitor of NADPH oxidase; 4-PBA: 4-phenylbutyrate, chemical chaperone; NAC: N-acetyl cysteine, antioxidant; GSH: glutathione, antioxidant. Data represent means \pm SD of triplicate measurements. ${ }^{*} p<0.05$ and ${ }^{* *} p<0.01$ according to one-way ANOVA as compared to control and MNPs@ $\mathrm{SiO}_{2}(\mathrm{RITC})$-treated BV2 cells, respectively
} 


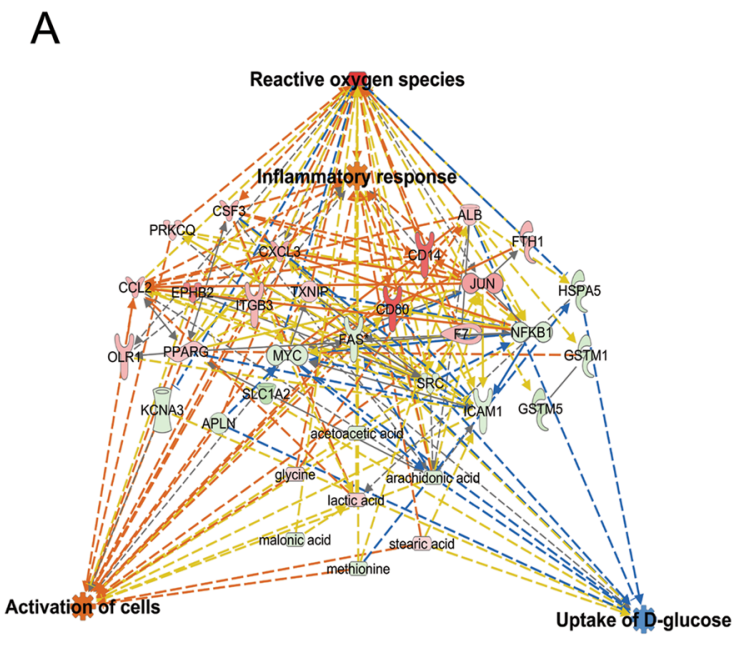

C

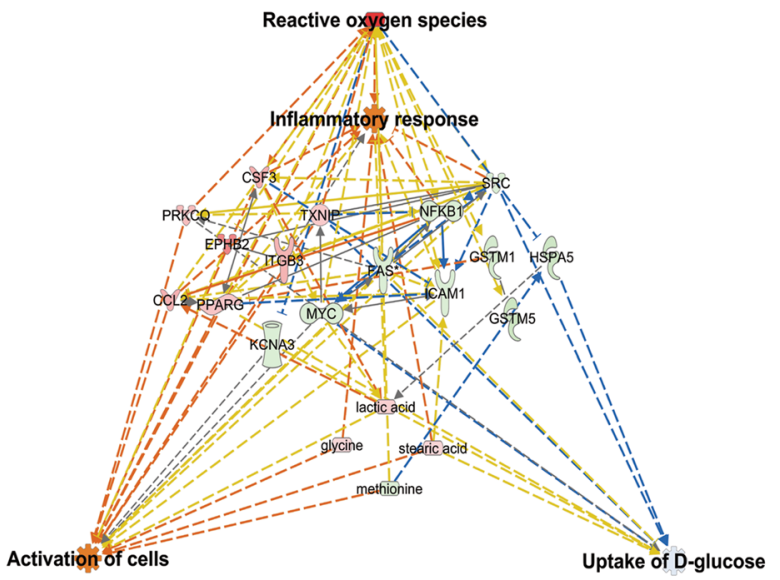

B
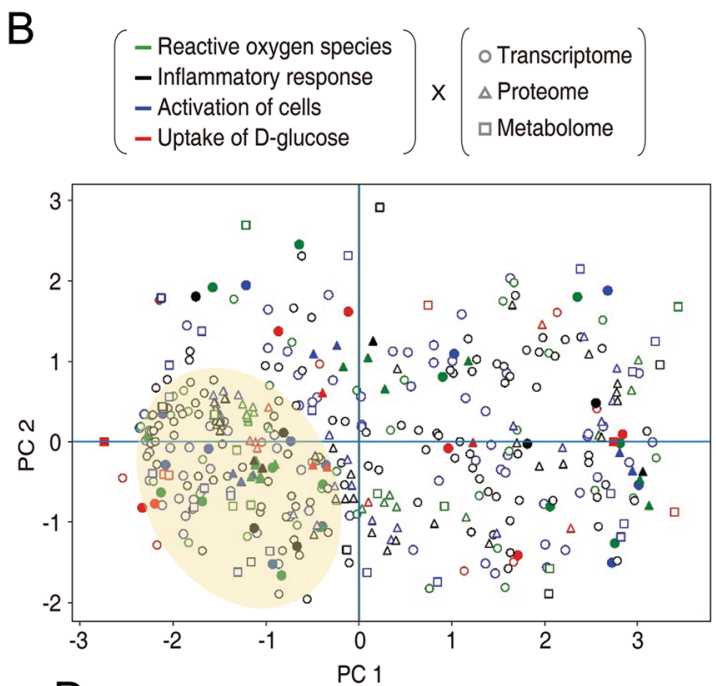

D

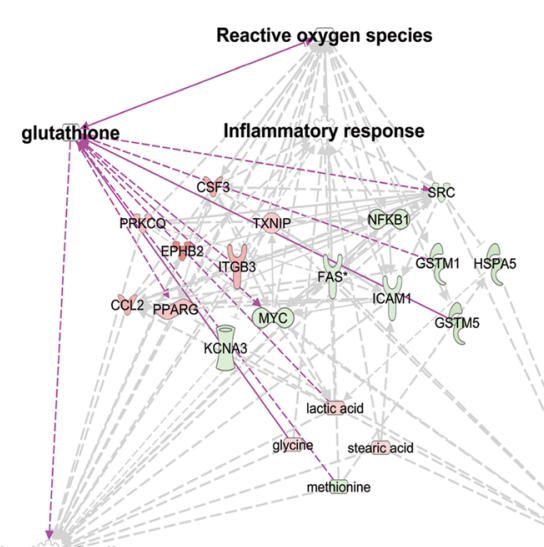

Uptake of D-glucose

$E$

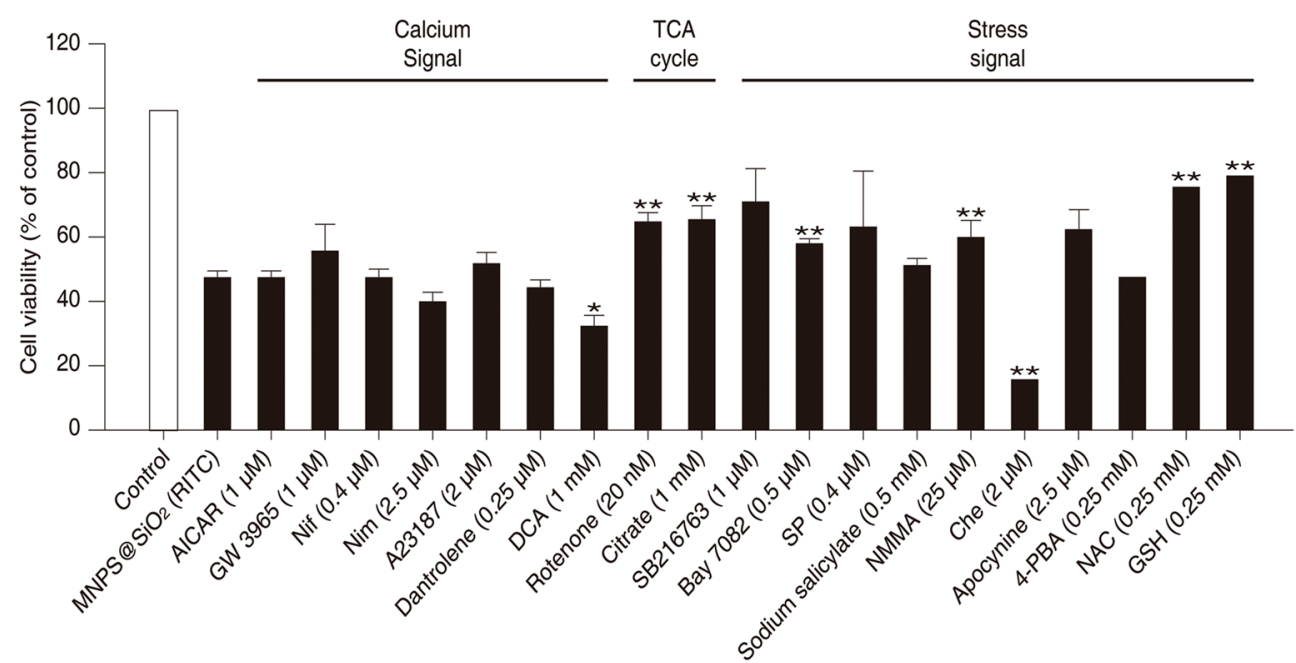

Fig. 4 (See legend on previous page.) 


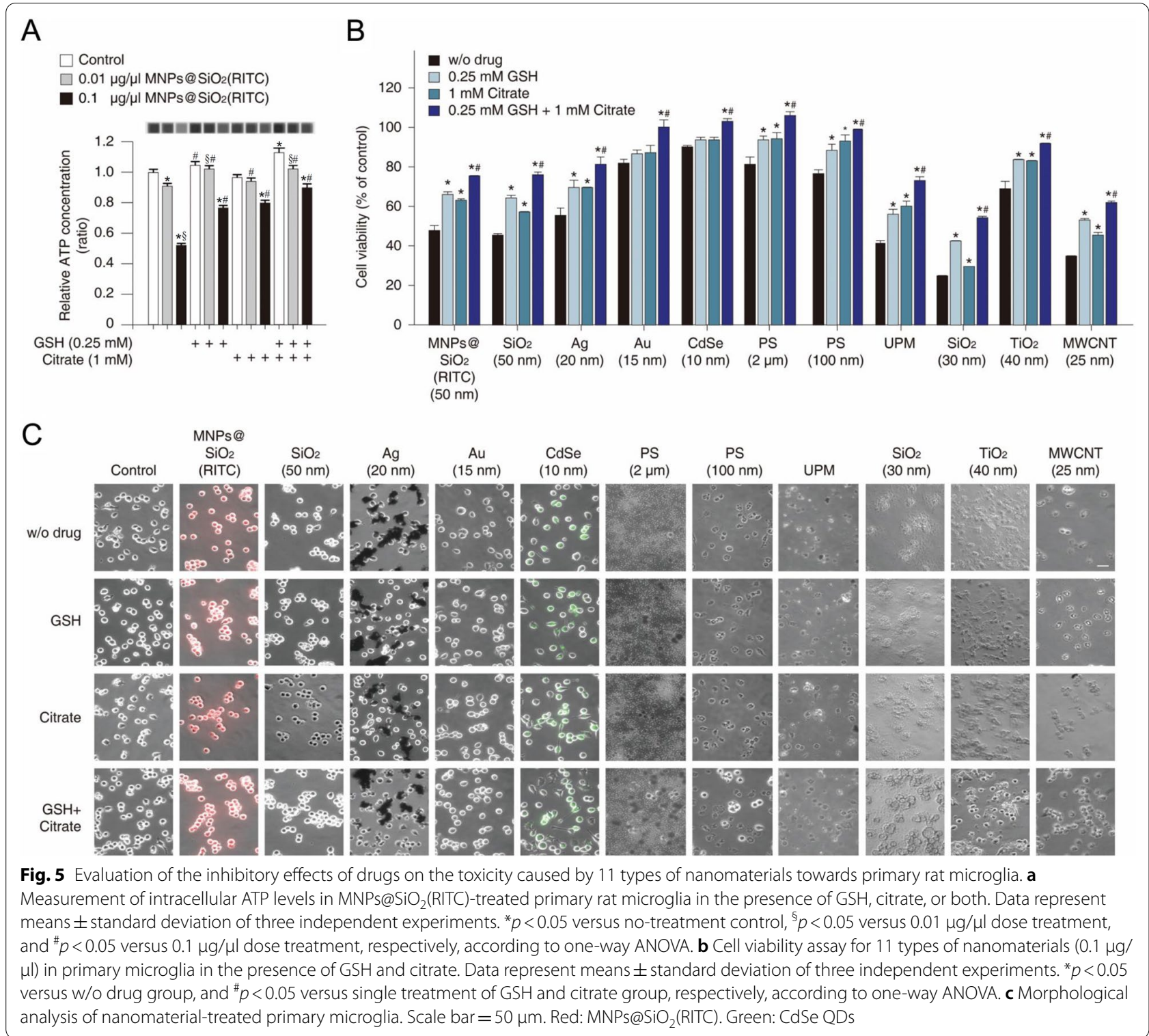

by $\sim 25 \%$ with each drug treatment alone and by $\sim 40 \%$ with the combination of drugs; Fig. 5a). To study the protective effects of GSH and citrate against the nanotoxicity induced by ten other kinds of nanomaterials, we treated BV2 cells with each nanomaterial $(0.1 \mu \mathrm{g} / \mu \mathrm{l})$ for $24 \mathrm{~h}$ in the presence of each drug or both drugs (Fig. 5b). Among the nanomaterials, $\mathrm{SiO}_{2}$ NPs $(30 \mathrm{~nm})$ were the most toxic: $\sim 75 \%$ of cells were dead in this condition. GSH attenuated nanomaterialinduced cell death by $\sim 15 \%$, whereas citrate reduced nanomaterial-induced cell death by $\sim 10 \%$ as compared to NP-challenged untreated cells. The combined (GSH-and-citrate) treatment alleviated this cell death by $\sim 25 \%$. Similarly, morphological analysis showed that the nanomaterial-induced cell death was attenuated by the co-treatment with the two drugs (Fig. 5c).

To assess the potential of MNPs@SiO ${ }_{2}(\mathrm{RITC})$ to cause nanotoxicity to microglia, mice were injected intraperitoneally with $\mathrm{MNPs@SiO}{ }_{2}(\mathrm{RITC})$ at a dose of $100 \mathrm{mg} /$ $\mathrm{kg}$ or co-treated with a combination of GSH and citrate for 5 days (Fig. 6a). The brains were divided into the cortex, striatum, cerebellum, hippocampus, and thalamus

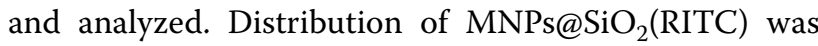
homogeneous across the brain, and these NPs accumulated preferentially in Iba1-positive microglia. Moreover, MNPs@SiO ${ }_{2}$ (RITC)-positive and Iba1-positive microglia showed morphological evidence of being activated. 3D reconstruction of these cells uncovered changes in the 
length of filaments of branch structures (Fig. 6b). In the hippocampus of MNPs@SiO $2(\mathrm{RITC})$-challenged mice, lengths of branch structures of microglia were significantly shorter, and this reduction was attenuated by coadministration of GSH and citrate (Fig. 6c). There were no changes in the brains of GSH-and-citrate-treated mice in the absence of MNPs@SiO ${ }_{2}$ (RITC) compared to controls. Moreover, there were no significant changes in the number of cells in the brain (Additional file 1: Fig. S35). In immunoblotting assays, Iba1, CD40, and CD11b expression levels were also higher in the brains of MNPs@SiO ${ }_{2}$ (RITC)-challenged mice. These increases were attenuated by co-administration of GSH and citrate (Fig. 6d-g). The microglial activation by MNPs@ $\mathrm{SiO}_{2}$ (RITC) and the attenuating effects of GSH and citrate also showed similar trends in the thalamus, cortex, striatum, and cerebellum (Fig. $6 \mathrm{~h}-\mathrm{m}$ and Additional file 1: Figs. S36-S38). The overall levels of microglial activation and the attenuating influence of co-administered GSH and citrate could be ranked as follows: hippocampus $>$ thalamus $>$ cerebellum $>$ striatum $>$ cortex .

\section{Discussion}

To our knowledge, this study is the first systems-biological analysis aimed at nanotoxicological evaluation using integrated triple omics. The resulting single network in microglia was trimmed by machine learning and used for in silico prediction before the screening of relevant drugs. Additionally, we propose that glutathione and citric acid reduce nanotoxicity by mostly targeting ROS production and utilization of energy, respectively.

We detected up-regulation of intracellular ROS, activation of microglia, and mitochondrial fission in MNPs@ $\mathrm{SiO}_{2}$ (RITC)-treated cells. Generally, oxidative stress triggers microglial activation [67], and morphological changes of microglia are an intrinsic and sensitive indicator of changes in the microenvironment of microglia [37]. Moreover, one study showed that mitochondrial fission can accompany ROS production and microglial activation [68]. The correlation between ROS and activation of microglia has been studied in pathological conditions involving up-regulation of ROS, e.g. aging, neurodegenerative diseases, and acute injury of the brain [69-71]. In the present study, we elucidated the relation between ROS and activation of microglia using TEM and integrated omics involving selected genes, proteins, and metabolites with high relevance. Considering the implications to pathological conditions and NP-induced biological changes, NPs also pose a risk of pathologic activation of microglia.

In this study, there were similar responses to MNPs@ $\mathrm{SiO}_{2}$ (RITC) (including increased ROS production, microglial activation, and reduced glucose uptake) between primary rat microglia and the BV2 cell line. Moreover, although the transcriptome, proteome, and metabolome were analyzed in MNPs@SiO $2(\mathrm{RITC})$-treated BV2 cells, the collected data were used to extrapolate the phenomena in primary microglial cells and in an in vivo mouse model. However, some studies have highlighted certain differences between these two cell types in their responses to LPS and TGF- $\beta$ in transcriptome and proteome analysis $[72,73]$, namely, primary microglia being more sensitive than BV2 cells. These discrepancies might be explained by complex biological effects of MNPs@ $\mathrm{SiO}_{2}(\mathrm{RITC})$ and their mechanism of action compared to LPS or TGF- $\beta$. There are no known proteins or other factors specific for binding to NPs [74], and our results indicate that a 1,000-fold higher concentration of MNPs@ $\mathrm{SiO}_{2}(\mathrm{RITC})$ than LPS is necessary to trigger microglial activation. Moreover, we hypothesized that the action of MNPs@SiO ${ }_{2}$ (RITC) in the cell is mostly based on ROS production, which can positively correlate with the efficiency of MNPs@SiO 2 (RITC) uptake. Thus, we found similar efficiency of $\mathrm{MNPs@SiO} 2(\mathrm{RITC})$ uptake between primary microglia and BV2 cells, and as a result, there were similar responses to MNPs@SiO 2 (RITC) between these cells.

Detachment of component, such as cobalt ferrite, RITC, and silica, from MNPs@SiO $2($ RITC) may occur in in vitro and in vivo in complex fluids. However, a previous in vitro study reported that RITC fluorescence intensity of $\mathrm{MNPs@SiO}$ (RITC) was reduced by $10 \%$

\footnotetext{
(See figure on next page.)

Fig. 6 Evaluation of MNPs@SiO $($ RITC)-induced microglial activation and effects of GSH and citrate in vivo. a Schematic of the in vivo experiment. b Immunohistochemical analysis of the hippocampal regions of the mouse brain. Low-magnification images are merged with florescence of Hoechst 33,342 (blue), MNPs@SiO 2 (RITC) (red), and Iba1 (green) to show region-specific structure and distribution of MNPs@SiO, (RITC). Black scale

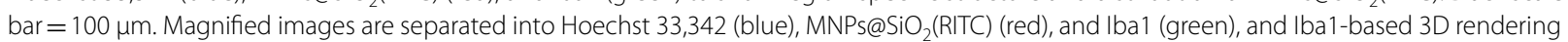
images. White scale bar $=10 \mu \mathrm{m}$. c Determined filament length from 3D rendering images of the hippocampus. $\mathbf{d}$ Representative immunoblotting data related to microglia activation. $\beta$-Actin served as an internal control. Normalized expression of Iba1 e, CD40 f, and CD11 b $\mathbf{g}$ in hippocampal tissue lysates. $\mathbf{h}$ Immunohistochemical analysis of the thalamus in the mouse brain. $\mathbf{i}$ Determined length of a filament from 3D rendering images of thalamic regions. $\mathbf{j}$ Representative immunoblotting data related to microglia activation. $\beta$-Actin was used as an internal control. Normalized expression of lba1 k, CD40 I, and CD $11 \mathrm{~b} \mathbf{m}$ in lysates of the thalamus. Data represent means \pm standard error of three independent experiments. ${ }^{*} p<0.05$ versus control, $p<0.05$ versus MNPs@SiO 2 (RITC)-treated mice according to one-way ANOVA
} 


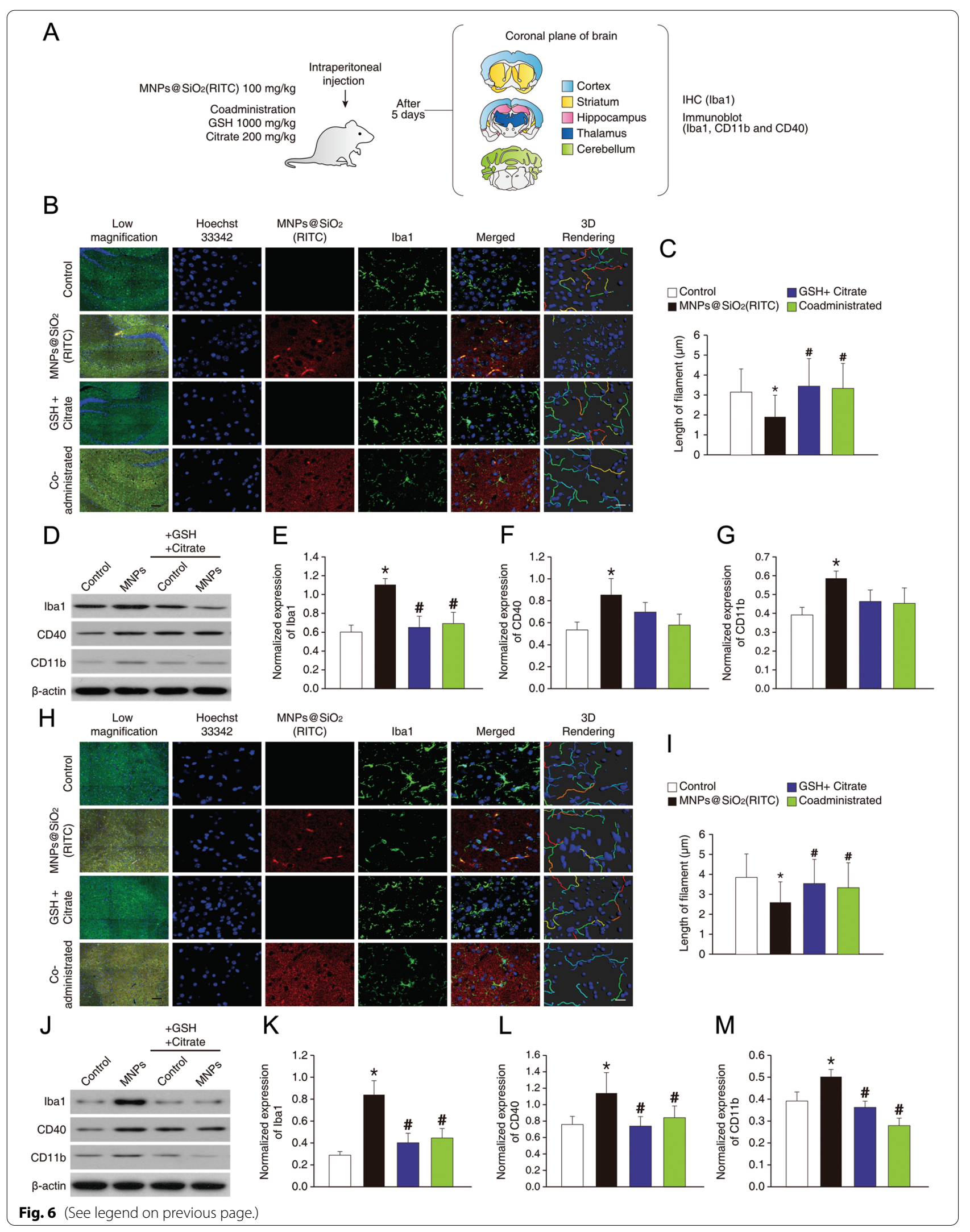


and $60 \%$ in the 3rd and 7th passages, respectively, in MNPs@SiO ${ }_{2}$ (RITC)-treated human cord blood-derived mesenchymal stem cells, and the reductions were suggested to be due to a dilution effect by cell proliferation [75]. Moreover, cobalt ferrite is more toxic than intact MNPs@SiO $\mathrm{Si}_{2}$ (RITC) [15, 51]; however, there was no significant reduction of cell viability in $\mathrm{MNPs@SiO}{ }_{2}(\mathrm{RITC})-$ treated HEK293 cells over 7 days. In addition, although MNPs@SiO ${ }_{2}$ (RITC) localized to various organs in mice treated with MNPs@SiO ${ }_{2}$ (RITC) for 4 weeks, an in vivo study revealed no pathological symptoms [26]. Thus, we assume that the MNPs@SiO $2(\mathrm{RITC})$ remains intact in complex biological fluid and the detachment of MNPs@ $\mathrm{SiO}_{2}$ (RITC) component may be considered in long-term exposure ( $>4$ weeks).

Previously, we demonstrated that changes in cells are induced by the silica shell of $\mathrm{MNPs@SiO}$ (RITC) rather than the $\mathrm{CoFe}_{2} \mathrm{O}_{3}$ core $[15,20,51,52]$, although the release of free metal ion from $\mathrm{SiO}_{2} \mathrm{NPs}$ into the cytosol up-regulating intracellular ROS has also been reported [76, 77]. Accordingly, we investigated ROS production induced by MNPs@SiO ${ }_{2}$ (RITC) [in comparison with silica NPs that are shall component of MNPs@SiO $2($ RITC)] or by a $\mathrm{CoFe}_{2} \mathrm{O}_{3}$ chemical at similar amount of the $\mathrm{CoFe}_{2} \mathrm{O}_{3}$ core in HEK293 cells treated with $0.1 \mu \mathrm{g} / \mu \mathrm{l}$ and $1.0 \mu \mathrm{g} / \mu \mathrm{l}$ MNPs@SiO${ }_{2}(\mathrm{RITC})$. The $\mathrm{CoFe}_{2} \mathrm{O}_{3}$ chemical caused elevated levels of ROS and reduced cell viability at $0.1 \mu \mathrm{g} / \mu \mathrm{l}$ and $1.0 \mu \mathrm{g} / \mu \mathrm{l}$ amount treatment, but ROS production was similar between the MNPs@SiO ${ }_{2}(\mathrm{RITC})$ and silica NP treated cells at both concentrations $0.1 \mu \mathrm{g} /$ $\mu \mathrm{l}$ and $1.0 \mu \mathrm{g} / \mu \mathrm{l}$ for 12,24 , and $48 \mathrm{~h}$. ROS production was induced by MNPs@SiO 2 (RITC) and by silica NPs at 0.01

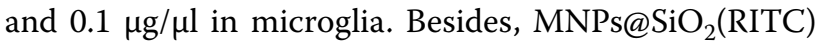
and silica NPs have similar biological effects [50]. These findings suggest that the elevation in intracellular ROS is due to the silica shell of MNPs@SiO 2 (RITC) and caused a dysfunction of glucose uptake by microglial cells. Furthermore, our results indicate that mitochondrial fission might be triggered by increased ROS generation due to $\mathrm{MNPs@SiO} \mathrm{Si}_{2}(\mathrm{RITC})$, and as a consequence, reduced ATP production and increased lactate concentration in MNPs@SiO ${ }_{2}$ (RITC)-treated cells. Similar findings have been reported in Ag NPs-treated hepatoma cells [78].

We found lower glucose uptake by MNPs@ $\mathrm{SiO}_{2}$ (RITC)-treated microglia with up-regulation of ROS, an inflammatory response, and activation of microglia during the computational prediction and in the actual experimental data. Moreover, one study emphasizes that $\mathrm{D}$-glucose uptake by microglia is regulated by glucose transporter 1 (GLUT1) under inflammation, and the metabolic mechanism is re-programmed by blockage of GLUT1 for regulation of microglial activation and neurodegeneration [79]. By contrast, we found that a reduction in $\mathrm{D}$-glucose uptake correlates inversely with microglia activation, according to in silico prediction by transcriptomic, proteomic, and metabolomic analyses, and there is no significant change in the expression of GLUT1. In this study, ROS turned out to be a major trigger of dysfunctions in microglia, whereas GSH attenuated the reduction in D-glucose uptake. In addition, in canonical signaling, crosstalk between hypoxia-inducible factor (HIF)- $1 \alpha$ and NF- $k B$, which are regulated by ROS, has been suggested [80], with HIF- $1 \alpha$ activating NF- $\mathrm{kB}$ with consequent increment of GLUT1 expression [81]. However, the GLUT1 expression at the transcriptional level decreased upon HIF- $1 \alpha$ inhibition by ROS in NPs-treated cells [82]. On the other hand, other studies reported that NPs treatment induces HIF- $1 \alpha$ and NF- $\mathrm{KB}$ activation [83, 84]. Thus, interpretation of nanotoxicity based on the canonical pathway remains controversial, and MNPs@SiO ${ }_{2}$ (RITC)-induced microglial activation is different from the canonical process of activating

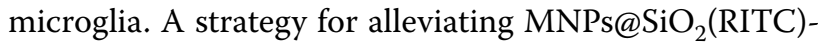
induced inflammation should be based on a comprehensive analysis.

Pathway analysis, one of the functional clustering (enrichment) techniques, is a useful tool for omics research. This method facilitates interpretation and hypothesis generation at the overwhelmingly large scale of experimental omics data, according to existing knowledge [14, 85-88]. Thus, researchers may gain insights into heterogeneous phenomena using pathway analysis with in silico prediction.

Pathway analysis of differentially expressed genes, proteins, and metabolites has limitation because the omics data are a snapshot of biological phenomena at a specific time point and cannot fully reflect the dynamics of the phenomena [89]. Moreover, the inter-dependence of biological functions may not be realized due to weak links among biological functions [89]. Additionally, bioinformatic tools for pathway analysis are created mostly on the basis of existing knowledge, hence, novel findings are limited [90, 91]. Thus, a non-canonical pathway cannot be found in pathway analysis, and each omics analysis can be biased, which could be deduced a false positive or negative result. In this study, we trimmed the triple-omics network-related factors by a machine learning-based unsupervised procedure with the $k$-NN algorithm for reducing biases in the analysis. By doing so, we noted stronger relationships of factors despite the observed functional differences. Thus, optimization of an algorithm and combination of analysis tools might be necessary for precise analysis and prediction of biological phenomena.

We detected a reduction in intracellular ATP concentration and an increase of lactate levels (Additional file 1: 
Tables S7 and S8) in MNPs@SiO ${ }_{2}(\mathrm{RITC})$-treated BV2 cells. Moreover, we examined intracellular accumulation of $\mathrm{MNPs@SiO} \mathrm{S}_{2}(\mathrm{RITC})$ and changes in cell ultrastructure using TEM. The most distinguishable changes in cell organelles were detected in mitochondria, which were segregated and showed small cross-sectional area and increased numbers, so called mitochondrial fission, in MNPs@SiO ${ }_{2}(\mathrm{RITC})$-treated BV2 cells. Some researchers demonstrated that mitochondrial fission can take place during oxidative damage, metabolic change, and other pathological conditions [92]. Moreover, in the mitochondrial fission state, cells utilise aerobic glycolysis, which generates ATP by converting glucose to lactate, in accordance with lower mitochondrial respiratory function for utilizing the TCA cycle [93]. Thus, due to mito-

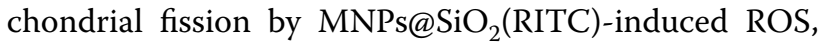
the level of lactate was higher in $\mathrm{MNPs@SiO} 2(\mathrm{RITC})$ treated BV2 cells.

GSH and citrate, which we found in the triple-omics network, efficiently reversed the nanotoxicity induced by NPs of various kinds and sizes. GSH is a natural antioxidant that regulates cellular redox homeostasis [94]. Citrate is a natural compound and can serve as a nutritional supplement for the cell as a TCA cycle intermediate [95]. Moreover, GSH and citrate have a chemical property of chelating metal ions [96], whereby they can reduce upregulation of intracellular calcium ion, which can induce apoptosis, while citrate can chelate an NP-derived toxic metal ion. We studied the protective effect against nanotoxicity in MNPs@SiO 2 (RITC)-treated BV2 cells using modulators affecting stress signalling, calcium signalling, lipid metabolism, the TCA cycle, and oxidative stress. Moreover, using triple-omics analysis in MNPs@ $\mathrm{SiO}_{2}$ (RITC)-treated BV2 cells, we found that ROS is highly related with genes, proteins, and metabolites that are involved in inflammatory response, activation of cells, and uptake of D-glucose in MNPs@SiO $\mathrm{Si}_{2}$ (RITC) treated microglia. We also found intracellular ATP levels to be decreased in MNPs@SiO 2 (RITC)-treated microglia, and TCA cycle energy metabolism was impaired by reduction of organic acids. In addition, GSH and citrate were identified from the triple-omics analysis, and their expected major mechanisms of action were found to be reduction of ROS production and supplementation of energy source, respectively. In addition, although we examine the nanotoxicity alleviation effect of intraperitoneal administration of glutathione and citrate in alleviating nanotoxicity in an in vivo mouse model, these compounds are orally bioavailable, making their broad application feasible $[97,98]$. We also suggest that strategies for developing drugs to control nanotoxicity should be based on inhibition of oxidative stress initiation, activation of energy generation, and reduction in the exposure to toxic metal ions. Further study is needed to analyse the alleviation of nanotoxicity by GSH and citrate using multi-omics in order to elucidate the detailed molecular mechanism(s) of their actions.

The toxicities of $\mathrm{SiO}_{2}$ NPs, Ag NPs, $\mathrm{Au}$ NPs, CdSe QDs, PSs, $\mathrm{TiO}_{2}$ NPs, UPM, and MWCNTs, which are produced from widespread minerals and used in daily life, were assessed at doses of 0.01 and $0.1 \mu \mathrm{g} / \mu \mathrm{l}$. In addition, the toxicity alleviation effects of GSH and citrate were observed in microglia for comparison with MNPs@ $\mathrm{SiO}_{2}(\mathrm{RITC})$-induced toxicity at 0.01 or $0.1 \mu \mathrm{g} / \mu \mathrm{l}$ doses, and investigation of versatile alleviation effects of GSH and citrate. Morphological activation of microglia was observed after a $12 \mathrm{~h}$ treatment with 0.01 and $0.1 \mu \mathrm{g} / \mu \mathrm{l}$ of $50 \mathrm{~nm} \mathrm{SiO} \mathrm{S}_{2} \mathrm{NPs}$, Ag NPs, Au NPs, and CdSe QDs. Cell death was observed in microglia treated for $12 \mathrm{~h}$ with 0.01 or $0.1 \mu \mathrm{g} / \mu \mathrm{l}$ doses of $2 \mu \mathrm{m}$ and $100 \mathrm{~nm}$ PSs, $\mathrm{TiO}_{2}$ NPs, $30 \mathrm{~nm} \mathrm{SiO} 2$ NPs, UPM, and MWCNTs, in a dose dependent manner. In a $24 \mathrm{~h}$ NP treatment with GSH and citrate, nanomaterial-induced cell death was attenuated, although the attenuation was deduced from omics analysis from MNPs@SiO ${ }_{2}$ (RITC) treated cells. With respect to nanomaterial stability in cell culture medium, Ag NPs, $2 \mu \mathrm{m}$ PSs, UPM, $30 \mathrm{~nm} \mathrm{SiO}{ }_{2}$ NPs, and $\mathrm{TiO}_{2}$ NPs were observed to aggregate and sediment in cell culture medium after incubation for $24 \mathrm{~h}$. Chemical dosimetry in vitro is important for assessment of nanomaterial toxicity $[99,100]$, and further physicochemical studies, including stability, hydrodynamic size, and agglomeration state, are required for proper dose-response assessment of each nanomaterial in in vitro studies.

In the in vivo mouse model, we found that administration of MNPs@SiO $\mathrm{S}_{2}$ (RITC) induces microglia activation in the brain, whereas co-administration of GSH and citric acid reduced this activation, consistently with our in vitro findings. The levels of microglial activation events varied among brain regions (the cortex, striatum, cerebellum, hippocampus, and thalamus), according to differences in BBB permeability in each region and accumulation of MNPs@SiO $\mathrm{S}_{2}$ (RITC) and drugs [30]. Although GSH and citric acid are physiologically present in the human body, their administration efficiently reduced MNPs@ $\mathrm{SiO}_{2}$ (RITC)-induced toxicity in the brain across the BBB. Additionally, the biodistribution and toxicological parameters of MNPs@SiO $2(\mathrm{RITC})$ were evaluated at 25,50 , and $100 \mathrm{mg} / \mathrm{kg}$ doses, and this study revealed no significant adverse effects, such as growth, behavioural changes, biochemical changes in serum, or histopathologic findings even at the $100 \mathrm{mg} / \mathrm{kg}$ dose [26]. Further studies are needed to evaluate the dose and temporal effects of NPs, GSH, citric acid, and other drugs in other organs, beyond the brain assessments performed in the present study. 
MNPs@SiO ${ }_{2}(\mathrm{RITC})$ accumulate in the liver, lungs, uterus, kidneys, testes, heart, spleen, and brain [26], after intraperitoneal administration in mice. MNPs@ $\mathrm{SiO}_{2}$ (RITC) penetrated the $\mathrm{BBB}$ and accumulated in the brain with time, as the intensity of its fluorescence increased in a time-dependent manner. Route of administration is an important factor for the biodistribution of substances in vivo $[101,102]$. In the case of NPs, they can be administrated through various routes for medical purposes including oral, pulmonary, transdermal, and intravenous [103], which results in their distribution and accumulation in organs through the blood and lymphatic circulatory systems $[104,105]$. Brain accumulation of NPs is determined by the penetration of the BBB, which comprises specialized structures with a basal lamina, microvessel endothelial cells, pericytes, and astrocytes $[30-32,106]$. Paracellular and transcytosis pathways are the two major paths for BBB penetration [106]. The paracellular pathway is induced by disruption of tight junctions and osmotic pressure with local permeability using additional support, such as ultrasound/microbubbles, but this additional support can be a contributing factor for loss of BBB function [107]. In turn, the transcytosis pathway can be classified as adsorptive, mediated by physicochemical interactions with cells, or receptor-mediated by binding to specific receptors [108]. In general, transcytosis is initiated by clathrin- and caveolin-mediated endocytosis and escape from the endocytosis vesicle [106]. In addition, the efficiency of endocytosis is determined by surface properties and NPs size [109]. Thus, the amount of total administrated MNPs@SiO 2 (RITC) localized to the brain varies based on route, which should be considered during the usage of nanomaterials for clinical purposes.

As mentioned earlier, MNPs@SiO ${ }_{2}$ (RITC) is assumed to remain intact in complex biological fluid and the effects of MNPs@SiO ${ }_{2}$ (RITC) are suggested to be exerted by the silica shell. BBB penetration and brain localization of silica NPs have been analyzed using inductively coupled plasma (ICP) techniques, TEM, and X-ray fluorescence (XRF) measurement in previous studies [110, 111]. Although we analyzed the fluorescence of MNPs@ $\mathrm{SiO}_{2}$ (RITC) to detect NP localization in the brain, there is a low possibility for false-positive detection (detached RITC). In addition, and theoretically, mice weighing $25 \mathrm{~g}$ have $\sim 2 \mathrm{ml}$ of total blood [112], and brain localization of administered NPs is $\sim 1 \%$ of the initial dose in biodistribution studies [110, 111]. Thus, $100 \mathrm{mg} / \mathrm{kg}$ $\left(2.5 \mathrm{mg} /\right.$ mouse $\left._{25 \mathrm{~g}}\right)$ of administered $\mathrm{MNPs} @ \mathrm{SiO}_{2}(\mathrm{RITC})$ may be localized at a concentration of $\sim 0.0125 \mu \mathrm{g} / \mu \mathrm{l}$ in the brain. Moreover, in this study, fluorescence intensity of neuronal cells in the brain was similar between brain slices of mice receiving $100 \mathrm{mg} / \mathrm{kg}$ and microglia treated with $\sim 0.01-0.1 \mu \mathrm{g} / \mu \mathrm{l}$ NPs in vitro. Moreover, Thus, to

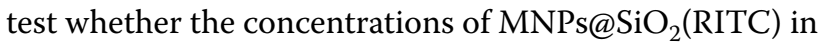
microglial cells in culture are related to those present in brain microglia, there is a pressing need for further clarification about the distribution of NPs in the brain using high-resolution confocal microscopy, X-ray absorption near edge structure spectroscopy, and inductively coupled plasma mass spectrometry for medical diagnostics and therapeutic applications.

Kim et al. [26] reported that serum biochemical changes, including glucose, cholesterol, creatinine, and the concentration ratio of aspartate transaminase and alanine transaminase were not detected in mice treated with 25,50 , and $100 \mathrm{mg} / \mathrm{kg}$ of MNPs@SiO${ }_{2}$ (RITC). Moreover, abnormal body weight change and behaviors were also not detected in a previous study [26]. Due to subtle toxicological phenotypes for MNPs@SiO $\mathrm{Si}_{2}$ (RITC) exposure, the nanotoxicity was not detected using conventional methods in in vitro and in vivo $[14,15,75]$; however, the toxicity of $\mathrm{MNPs@SiO}{ }_{2}$ (RITC) has been analyzed using integrated omics and mechanobiology $[13,15,17,20,25$, 51, 52]. In this study, we analyzed changes in the MNPs@ $\mathrm{SiO}_{2}$ (RITC)-exposure related biological functions using triple omics integration in in vitro studies, and we extrapolated the effect of MNPs@SiO ${ }_{2}(\mathrm{RITC})$ exposure on an in vivo mouse model. Although intravenous injection is a more proper route for administering contrast agents to organs for rapid delivery, when considering the onset of action, than is intraperitoneal injection [113], the in vivo experiment was performed using the same conditions, including mice species, the highest MNPs@ $\mathrm{SiO}_{2}$ (RITC) dose, and injection route, of the Kim et al. study. No abnormal body weight change nor behaviors were detected. However, in this study, the extrapolated biological function, microglial activation, was detected in MNPs@SiO ${ }_{2}$ (RITC) treated mice brain. Thus, our results suggest that an in vitro investigation is highly recommended to precede a subtle toxicological assessment in in vivo.

MNPs@SiO ${ }_{2}$ (RITC) were preferentially taken up by microglia than neuronal cells in in vitro and in vivo. Previous studies also reported higher uptake efficiencies by microglia over that of other neuroglia and neurons $[33,114]$, consistent with the results of our study. In addition to utilizing internalization mechanisms such as clathrin- and caveolin-dependent endocytosis and pinocytosis [115-117], microglia have more highly developed phagocytosis than neurons, with higher expression of phagocytosis related genes, including the triggering receptor expressed on myeloid cells 2 (TREM2), platelet glycoprotein 4, fatty acid translocase ( $F A T$, also known as CD36), CCAAT enhancer-binding protein alpha $(C /$ $E B P \alpha)$, leucine-rich repeat kinase 2 (LRRK2), lysosomal 
associated membrane protein 3 ( $L A M P 3$, also known as CD 208), and lysosomal associated membrane protein 4 (LAMP4, also known as CD68) [114, 118]. This might explain the increased uptake of nanoparticles by microglia compared to neurons. Additionally, we found that the uptake of MNPs@SiO 2 (RITC) by microglia was associated with phagocytosis, whereas the exocytosis process turned out to be suppressed in the triple-omics network analysis (Additional file 1: Figs. S39 and S40 and Table S11) and in the prediction of the triple omics network in MNPs@SiO ${ }_{2}$ (RITC)-treated BV2 cells (Additional file 1: Figs. S41 and S42). Particle transport into cells is physically mediated by diffusion (size fraction $25-50 \mathrm{~nm}$ ), sedimentation (size fraction $250-500 \mathrm{~nm}$ ), and agglomeration in a particle density (concentration)-dependent manner [119]. In addition, cells uptake NPs through clathrin-mediated endocytosis (endocytic vesicle size: $\sim 100 \mathrm{~nm}$ ), caveolaemediated endocytosis (endocytic vesicle size: $\sim 60 \mathrm{~nm}$ ), clathrin-caveolin-independent endocytosis (endocytic vesicle size: $\sim 100 \mathrm{~nm}$ ), micropinocytosis (endocytic vesicle size: $>200 \mathrm{~nm}$ ), and phagocytosis (endocytic vesicle size: $>200 \mathrm{~nm}$ ), according to size, shape, and physicochemical properties of the NPs $[120,121]$. In our results, diameters of vesicles containing >30 MNPs@ $\mathrm{SiO}_{2}(\mathrm{RITC})$ agglomerates in the MNPs@SiO $2(\mathrm{RITC})-$ treated microglial cells were greater than $500 \mathrm{~nm}$, implying that the endocytic process was dominantly micropinocytosis or phagocytosis [122, 123]. Moreover, morphological activation is also called 'phagocytic activation' and indicates that the phagocytic pathway is dominant in this state [124]. On the other hand, the phagocytic pathway is not highly developed in other cell types [122]. Suppression of exocytosis may be fundamentally related to nanotoxicity due to the resistance of NPs to biodegradation. Therefore, high uptake efficiency in microglia might be mediated by phagocytosis, which is highly developed in the macrophage lineage $[114,118]$, and activation of exocytosis in the cells taking up NPs may be one of the strategies for reducing nanotoxicity.

\section{Conclusions}

This study suggests that exposure to $0.1 \mu \mathrm{g} / \mu \mathrm{l}$ dose of MNPs@SiO ${ }_{2}(\mathrm{RITC})$ can cause ROS production, inflammatory response, microglial activation, and a glucose metabolism disorder according to integral analysis using computational prediction by means of triple omics, as compared to $0.01 \mu \mathrm{g} / \mu \mathrm{l}$ dose of $\mathrm{MNPs} @ \mathrm{SiO}_{2}$ (RITC) in microglia. These findings highlight the importance of using appropriate doses of NPs in terms of possible adverse effects and may help to develop new drugs reducing nanotoxicity.

\section{Abbreviations}

AAs: Amino acids; ANOVA: One-way analysis of variance; BBB: Blood-brain barrier; C/EBPa: CCAAT enhancer-binding protein alpha; $\mathrm{CoFe}_{2} \mathrm{O}_{3}$ : Cobalt ferrite; ECL: Enhanced chemiluminescence; EOC: Ethoxycarbonyl; FAs: Fatty acids; FAT: Platelet glycoprotein 4, fatty acid translocase; G6PDH: Glucose-6-phosphate dehydrogenase; GC-MS/MS: Gas chromatography with tandem mass spectrometry; GLUT1: Glucose transporter 1; GSH: Glutathione; HIF: Hypoxiainducible factor; HSD: Tukey's honestly significant difference; ICP: Inductively coupled plasma; IPA: Ingenuity pathway analysis; $k$-NN: $k$-Nearest neighbor; LAMP3: Lysosomal associated membrane protein 3; LAMP4: Lysosomal associated membrane protein 4; LC-MS/MS: Liquid chromatography with tandem mass spectrometry; LPS: Lipopolysaccharide; LRRK2: Leucine-rich repeat kinase 2; MEM: Minimum essential medium; MNPs: Magnetic nanoparticles; MNPs@SiO 2 (RITC): Silica-coated-magnetic nanoparticles containing the rhodamine B isothiocyanate dye; MO: Methoxime; MWCNTs: Multi-walled carbon nanotubes; NAC: N-Acetyl cysteine; $\mathrm{NADP}^{+}$: Nicotinamide adenine dinucleotide phosphate; Nanotoxicity: Nanomaterial-induced toxicity; NeuN: Neuronal nuclei; NIST: National Institute of Standards and Technology; NMMA: _-NGmonomethyl-_-arginine; NPs: Nanoparticles; OAs: Organic acids; OD: Outer diameter; PCA: Principal component analysis; PSs: Polystyrene particles; QDs: Quantum dots; qPCR: Quantitative PCR; ROS: Reactive oxygen species; TBDMS: tert-Butyldimethylsilyl; TCA: Tricarboxylic acid; TEM: Transmission electron microscopy; TH: Tyrosine hydroxylase; TREM2: Triggering receptor expressed on myeloid cells 2; UPM: Urban particulate matter; XRF: X-ray fluorescence.

\section{Supplementary Information}

The online version contains supplementary material available at https://doi. org/10.1186/s12989-021-00433-y.

Additional file 1: Supplementary Materials.

\section{Acknowledgements}

The authors would like to thank Bunsoon Choi, Ji Eun Lee, Sinae Ahn, Sun Young Che, and the Ajou Core-Facility Center for technical assistance and cell image analysis.

\section{Authors' contributions}

Conceptualization, T.H.S. and G.L.; Data curation, T.H.S., D.Y.L., C.S., H.S., and J.Y.L.; Formal analysis, A.Y.K. and J.M.C.; Funding acquisition, T.H.S., J.Y.K., M.M.M., and G.L.; Investigation, T.H.S., B.M., S.B., M.J.P., S.W.K., and J.Y.K.; Methodology, T.H.S., B.M., S.B., M.J.P., S.W.K., and J.Y.K.; Project administration, G.L.; Resources, D-.K.C. and E.J.B.; Software, T.H.S., B.M., and S.B.; Supervision, G.L.; Validation, T.H.S., B.M., S.B., M.J.P., S.W.K., and J.Y.K.; Visualization, T.H.S.; Roles/Writingoriginal draft, T.H.S. and G.L.; Writing-review \& editing, E.J.B., S.H.K., D-.K.C., Y.K., and M.M.M. All authors read and approved the final manuscript.

\section{Funding}

This work was supported by Grants from the National Research Foundation (NRF) funded by the Ministry of Science and ICT (MSIT) in Korea [2018R1D1A1B07049494, 2020R1C1C1008366, 2020R1A4A4079722, 2020M3E5D9080661, and 2021R1A5A6002853], a Grant from the Korea Basic Science Institute (KBSI) [Grant No. C170100]. M.M.M. is the William Dow Lovett Professor of Neurology and is supported by Grants from the US National Institutes of Health (NIH) (NS101134, NS096032, AT006868, and NS073994), the Michael J. Fox Foundation for Parkinson's Research and the American Parkinson Disease Association.

\section{Availability of data and materials}

The data supporting the findings of this study are available from the corresponding author, upon reasonable request. Transcriptome sequencing and quantification data are available in the GEO database under the following accession number: GSE154250. Proteome and quantification data are available in PRIDE with following accession number: PXD020225. 


\section{Declarations}

\section{Ethical approval and consent to participate}

All animal experimental protocols were approved by the Laboratory Animal Research Center of Ajou University Medical Center (approval no. 2020-0033) and complied with the institutional ethical use protocols (NIH Guide for Care and Use of Laboratory Animals).

\section{Competing interests}

The authors declare that they have no competing interests.

\section{Author details}

${ }^{1}$ Department of Physiology, Ajou University School of Medicine, 206 World cup-ro, Suwon 16499, Republic of Korea. ${ }^{2}$ College of Pharmacy, Sunchon National University, 255 Jungang-ro, Suncheon 57922, Republic of Korea. ${ }^{3}$ Department of Molecular Science and Technology, Ajou University, 206 World cup-ro, Suwon 16499, Republic of Korea. ${ }^{4}$ Research Center of Bioconvergence Analysis, Korea Basic Science Institute, 162 Yeongudanji-ro, Cheongju 28119, Republic of Korea. ${ }^{5}$ Department of Chemistry, Graduate School, Kyung Hee University, Yongin-si, Gyeonggi-do 17104, Republic of Korea. ${ }^{6}$ Department of Applied Chemistry and Institute of Natural Sciences, Kyung Hee University, Yongin-si, Gyeonggi-do 17104, Republic of Korea. ${ }^{7}$ Department of Biotechnology, College of Biomedical and Health Science, Konkuk University, 268 Chungwondaero, Chungju 27478, Republic of Korea. ${ }^{8}$ RWJMS Institute for Neurological Therapeutics, Rutgers Biomedical and Health Sciences, and Department of Neurology, Robert Wood Johnson Medical School, Rutgers University, Piscataway, NJ 08854, USA. ${ }^{9}$ Department of Molecular Science and Technology, Ajou University, Suwon-si, Gyeonggi-do 16499, Republic of Korea. ${ }^{10}$ Department of Physiology, Ajou University School of Medicine, Suwon-si, Gyeonggi-do 16499, Republic of Korea.

Received: 20 May 2021 Accepted: 25 October 2021

Published online: 25 November 2021

\section{References}

1. Yoon TJ, Kim JS, Kim BG, Yu KN, Cho MH, Lee JK. Multifunctional nanoparticles possessing a "magnetic motor effect" for drug or gene delivery. Angew Chem Int Ed Engl. 2005;44:1068-71.

2. Ding YF, Li S, Liang L, Huang Q, Yuwen L, Yang W, Wang R, Wang LH. Highly biocompatible chlorin e6-loaded chitosan nanoparticles for improved photodynamic cancer therapy. ACS Appl Mater Interfaces. 2018;10:9980-7.

3. Delyagina E, Schade A, Scharfenberg D, Skorska A, Lux C, Li W, Steinhoff G. Improved transfection in human mesenchymal stem cells: effective intracellular release of pDNA by magnetic polyplexes. Nanomedicine (Lond). 2014;9:999-1017.

4. Patitsa M, Karathanou K, Kanaki Z, Tzioga L, Pippa N, Demetzos C, Verganelakis DA, Cournia Z, Klinakis A. Magnetic nanoparticles coated with polyarabic acid demonstrate enhanced drug delivery and imaging properties for cancer theranostic applications. Sci Rep. 2017:7:775.

5. Helal-Neto E, de Barros AO, Saldanha-Gama R, Brandão-Costa R, Alencar LM, dos Santos CC, Martínez-Máñez R, Ricci-Junior E, Alexis F, Morandi V, et al. Molecular and cellular risk assessment of healthy human cells and cancer human cells exposed to nanoparticles. Int J Mol Sci. 2020;21:230.

6. Stark WJ. Nanoparticles in biological systems. Angew Chem Int Ed Engl. 2011;50:1242-58

7. Qi R, Wang Y, Bruno PM, Xiao H, Yingjie Y, Li T, Lauffer S, Wei W, Chen Q, Kang $X$, et al. Nanoparticle conjugates of a highly potent toxin enhance safety and circumvent platinum resistance in ovarian cancer. Nat Commun. 2017:8:2166.

8. Hawkins SJ, Crompton LA, Sood A, Saunders M, Boyle NT, Buckley A, Minogue AM, McComish SF, Jimenez-Moreno N, Cordero-Llana O, et al. Nanoparticle-induced neuronal toxicity across placental barriers is mediated by autophagy and dependent on astrocytes. Nat Nanotechnol. 2018;13:427-33

9. Guo M, Xu X, Yan X, Wang S, Gao S, Zhu S. In vivo biodistribution and synergistic toxicity of silica nanoparticles and cadmium chloride in mice. J Hazard Mater. 2013;260:780-8.
10. Auffan M, Rose J, Bottero JY, Lowry GV, Jolivet JP, Wiesner MR. Towards a definition of inorganic nanoparticles from an environmental, health and safety perspective. Nat Nanotechnol. 2009;4:634-41.

11. Krug HF, Wick P. Nanotoxicology: an interdisciplinary challenge. Angew Chem Int Ed Engl. 2011;50:1260-78.

12. Chen R, Huo L, Shi X, Bai R, Zhang Z, Zhao Y, Chang Y, Chen C. Endoplasmic reticulum stress induced by zinc oxide nanoparticles is an earlier biomarker for nanotoxicological evaluation. ACS Nano. 2014;8:2562-74.

13. Shin TH, Seo C, Lee DY, Ji M, Manavalan B, Basith S, Chakkarapani SK, Kang SH, Lee G, Paik MJ, Park CB. Silica-coated magnetic nanoparticles induce glucose metabolic dysfunction in vitro via the generation of reactive oxygen species. Arch Toxicol. 2019;93:1201-12.

14. Shin TH, Lee DY, Lee HS, Park HJ, Jin MS, Paik MJ, Manavalan B, Mo JS, Lee $\mathrm{G}$. Integration of metabolomics and transcriptomics in nanotoxicity studies. BMB Rep. 2018;51:14-20.

15. Shim W, Paik MJ, Nguyen DT, Lee JK, Lee Y, Kim JH, Shin EH, Kang JS, Jung HS, Choi S, et al. Analysis of changes in gene expression and metabolic profiles induced by silica-coated magnetic nanoparticles. ACS Nano. 2012;6:7665-80.

16. Fu PP, Xia Q, Hwang HM, Ray PC, Yu H. Mechanisms of nanotoxicity: generation of reactive oxygen species. J Food Drug Anal. 2014;22:6475. https://doi.org/10.1016/j.jfda.2014.01.005.

17. Shin TH, Lee DY, Ketebo AA, Lee S, Manavalan B, Basith S, Ahn C, Kang SH, Park S, Lee G. Silica-coated magnetic nanoparticles decrease human bone marrow-derived mesenchymal stem cell migratory activity by reducing membrane fluidity and impairing focal adhesion. Nanomaterials (Basel). 2019;9:1475

18. Yu Y, Duan J, Yu Y, Li Y, Liu X, Zhou X, Ho KF, Tian L, Sun Z. Silica nanoparticles induce autophagy and autophagic cell death in HepG2 cells triggered by reactive oxygen species. J Hazard Mater. 2014;270:176-86.

19. Liu X, Lu B, Fu J, Zhu X, Song E, Song Y. Amorphous silica nanoparticles induce inflammation via activation of NLRP3 inflammasome and HMGB1/TLR4/MYD88/NF-kb signaling pathway in HUVEC cells. J Hazard Mater. 2021;404:124050.

20. Shin TH, Ketebo AA, Lee DY, Lee S, Kang SH, Basith S, Manavalan B, Kwon DH, Park S, Lee G. Decrease in membrane fluidity and traction force induced by silica-coated magnetic nanoparticles. J Nanobiotechnology. 2021;19:21.

21. Wigner P, Zielinski K, Michlewska S, Danielska P, Marczak A, Ricci EJ, Santos-Oliveira R, Szwed M. Disturbance of cellular homeostasis as a molecular risk evaluation of human endothelial cells exposed to nanoparticles. Sci Rep. 2021:11:3849.

22. Wang S, Li F, Hu X, Lv M, Fan C, Ling D. Tuning the intrinsic nanotoxicity in advanced therapeutics. Adv Ther. 2018;1:1800059.

23. Ryu YS, Kang KA, Piao MJ, Ahn MJ, Yi JM, Hyun YM, Kim SH, Ko MK, Park CO, Hyun JW. Particulate matter induces inflammatory cytokine production via activation of NFkappaB by TLR5-NOX4-ROS signaling in human skin keratinocyte and mouse skin. Redox Biol. 2019;21:101080.

24. Mushtaq G, Khan JA, Joseph E, Kamal MA. Nanoparticles, neurotoxicity and neurodegenerative diseases. Curr Drug Metab. 2015;16:676-84.

25. Shin TH, Lee DY, Manavalan B, Basith S, Na Y-C, Yoon C, Lee H-S, Paik MJ, Lee G. Silica-coated magnetic nanoparticles activate microglia and induce neurotoxic d-serine secretion. Part Fibre Toxicol. 2021;18:30.

26. Kim JS, Yoon TJ, Yu KN, Kim BG, Park SJ, Kim HW, Lee KH, Park SB, Lee JK, Cho $\mathrm{MH}$. Toxicity and tissue distribution of magnetic nanoparticles in mice. Toxicol Sci. 2006;89:338-47.

27. Zhou Y, Peng Z, Seven ES, Leblanc RM. Crossing the blood-brain barrier with nanoparticles. J Control Release. 2018;270:290-303.

28. Koffie RM, Farrar CT, Saidi LJ, William CM, Hyman BT, Spires-Jones TL. Nanoparticles enhance brain delivery of blood-brain barrier-impermeable probes for in vivo optical and magnetic resonance imaging. Proc Natl Acad Sci U S A. 2011:108:18837-42.

29. Kong SD, Lee J, Ramachandran S, Eliceiri BP, Shubayev VI, Lal R, Jin S. Magnetic targeting of nanoparticles across the intact blood-brain barrier. J Control Release. 2012;164:49-57.

30. Phares TW, Kean RB, Mikheeva T, Hooper DC. Regional differences in blood-brain barrier permeability changes and inflammation in the apathogenic clearance of virus from the central nervous system. J Immunol. 2006;176:7666-75.

31. Wilhelm I, Nyul-Toth A, Suciu M, Hermenean A, Krizbai IA. Heterogeneity of the blood-brain barrier. Tissue Barriers. 2016:4:e1143544 
32. Kiyatkin EA, Sharma HS. Permeability of the blood-brain barrier depends on brain temperature. Neuroscience. 2009;161:926-39.

33. Kirschbaum K, Sonner JK, Zeller MW, Deumelandt K, Bode J, Sharma R, Kruwel T, Fischer M, Hoffmann A, Costa da Silva M, et al. In vivo nanoparticle imaging of innate immune cells can serve as a marker of disease severity in a model of multiple sclerosis. Proc Natl Acad Sci U S A. 2016;113:13227-32.

34. Perry $\vee H$. A revised view of the central nervous system microenvironment and major histocompatibility complex class II antigen presentation. J Neuroimmunol. 1998;90:113-21.

35. Voisin P, Ribot EJ, Miraux S, Bouzier-Sore AK, Lahitte JF, Bouchaud V, Mornet S, Thiaudiere E, Franconi JM, Raison L, et al. Use of lanthanide-grafted inorganic nanoparticles as effective contrast agents for cellular uptake imaging. Bioconjug Chem. 2007;18:1053-63.

36. Choi J, Zheng Q, Katz HE, Guilarte TR. Silica-based nanoparticle uptake and cellular response by primary microglia. Environ Health Perspect. 2010;118:589-95.

37. Fernandez-Arjona MDM, Grondona JM, Granados-Duran P, Fernandez-Llebrez P, Lopez-Avalos MD. Microglia morphological categorization in a rat model of neuroinflammation by hierarchical cluster and principal components analysis. Front Cell Neurosci. 2017;11:235.

38. Fiebich BL, Batista CRA, Saliba SW, Yousif NM, de Oliveira ACP. Role of microglia TLRs in neurodegeneration. Front Cell Neurosci. 2018;12:329.

39. Gottschall PE, Komaki G, Arimura A. Increased circulating interleukin-1 and interleukin-6 after intracerebroventricular injection of lipopolysaccharide. Neuroendocrinology. 1992;56:935-8.

40. Banks WA, Gray AM, Erickson MA, Salameh TS, Damodarasamy M, Sheibani N, Meabon JS, Wing EE, Morofuji Y, Cook DG, Reed MJ. Lipopolysaccharide-induced blood-brain barrier disruption: roles of cyclooxygenase, oxidative stress, neuroinflammation, and elements of the neurovascular unit. J Neuroinflamm. 2015;12:223.

41. Banks WA, Robinson SM. Minimal penetration of lipopolysaccharide across the murine blood-brain barrier. Brain Behav Immun. 2010;24:102-9.

42. Tynan RJ, Weidenhofer J, Hinwood M, Cairns MJ, Day TA, Walker FR. A comparative examination of the anti-inflammatory effects of SSRI and SNRI antidepressants on LPS stimulated microglia. Brain Behav Immun. 2012;26:469-79.

43. McGruder ED, Moore GM. Use of lipopolysaccharide (LPS) as a positive control for the evaluation of immunopotentiating drug candidates in experimental avian colibacillosis models. Res Vet Sci. 1999;66:33-7.

44. Reyes VC, Li M, Hoek EM, Mahendra S, Damoiseaux R. Genome-wide assessment in Escherichia coli reveals time-dependent nanotoxicity paradigms. ACS Nano. 2012;6:9402-15.

45. Verano-Braga T, Miethling-Graff R, Wojdyla K, Rogowska-Wrzesinska A, Brewer JR, Erdmann H, Kjeldsen F. Insights into the cellular response triggered by silver nanoparticles using quantitative proteomics. ACS Nano. 2014;8:2161-75.

46. Bo Y, Jin C, Liu Y, Yu W, Kang H. Metabolomic analysis on the toxicological effects of $\mathrm{TiO}(2)$ nanoparticles in mouse fibroblast cells: from the perspective of perturbations in amino acid metabolism. Toxicol Mech Methods. 2014;24:461-9.

47. Zhao Y, Li L, Zhang PF, Shen W, Liu J, Yang FF, Liu HB, Hao ZH. Differential regulation of gene and protein expression by zinc oxide nanoparticles in hen's ovarian granulosa cells: specific roles of nanoparticles. PLoS ONE. 2015:10:e0140499.

48. Van Assche R, Broeckx V, Boonen K, Maes E, De Haes W, Schoofs L, Temmerman L. Integrating-omics: systems biology as explored through $C$. elegans research. J Mol Biol. 2015;427:3441-51.

49. Sun YV, Hu YJ. Integrative analysis of multi-omics data for discovery and functional studies of complex human diseases. Adv Genet. 2016;93:147-90.

50. Beck GR Jr, Ha SW, Camalier CE, Yamaguchi M, Li Y, Lee JK, Weitzmann MN. Bioactive silica-based nanoparticles stimulate bone-forming osteoblasts, suppress bone-resorbing osteoclasts, and enhance bone mineral density in vivo. Nanomedicine. 2012;8:793-803.

51. Phukan G, Shin TH, Shim JS, Paik MJ, Lee JK, Choi S, Kim YM, Kang SH, Kim HS, Kang Y, et al. Silica-coated magnetic nanoparticles impair proteasome activity and increase the formation of cytoplasmic inclusion bodies in vitro. Sci Rep. 2016;6:29095.

52. Ketebo AA, Shin TH, Jun M, Lee G, Park S. Effect of silica-coated magnetic nanoparticles on rigidity sensing of human embryonic kidney cells. J Nanobiotechnol. 2020;18:170.

53. Seo H, Kim S-W. In situ synthesis of CdTe/CdSe core-shell quantum dots. Chem Mater. 2007;19:2715-7.

54. Kim J, Lee JE, Lee J, Jang Y, Kim S-W, An K, Yu JH, Hyeon T. Generalized fabrication of multifunctional nanoparticle assemblies on silica spheres. Angew Chem Int Ed. 2006;45:4789-93. https://doi.org/10.1002/ange. 200504107.

55. Wang AL, Yu AC, Lau LT, Lee C, le Wu M, Zhu X, Tso MO. Minocycline inhibits LPS-induced retinal microglia activation. Neurochem Int. 2005:47:152-8

56. Long TC, Saleh N, Tilton RD, Lowry GV, Veronesi B. Titanium dioxide (P25) produces reactive oxygen species in immortalized brain microglia (BV2): implications for nanoparticle neurotoxicity. Environ Sci Technol. 2006:40:4346-52.

57. Liang H, Chen A, Lai X, Liu J, Wu J, Kang Y, Wang X, Shao L. Neuroinflammation is induced by tongue-instilled $\mathrm{ZnO}$ nanoparticles via the $\mathrm{Ca} 2+-$ dependent NF-KB and MAPK pathways. Part Fibre Toxicol. 2018;15:39.

58. Stein DR, Hu X, McCorrister SJ, Westmacott GR, Plummer FA, Ball TB, Carpenter MS. High pH reversed-phase chromatography as a superior fractionation scheme compared to off-gel isoelectric focusing for complex proteome analysis. Proteomics. 2013;13:2956-66.

59. Jin C, Kim S, Kang H, Yun KN, Lee Y, Zhang Y, Kim Y, Kim JY, Han K. Shank3 regulates striatal synaptic abundance of $C y l d$, a deubiquitinase specific for Lys63-linked polyubiquitin chains. J Neurochem. 2019;150:776-86.

60. Ringner M. What is principal component analysis? Nat Biotechnol. 2008;26:303-4.

61. Pedregosa F, Varoquaux G, Gramfort A, Michel V, Thirion B, Grisel O, Blondel M, Prettenhofer P, Weiss R, Dubourg V, et al. Scikit-learn: machine learning in python. J Mach Learn Res. 2011;12:2825-30.

62. Baginsky S, Hennig L, Zimmermann P, Gruissem W. Gene expression analysis, proteomics, and network discovery. Plant Physiol. 2010:152:402-10.

63. Seyfried NT, Dammer EB, Swarup V, Nandakumar D, Duong DM, Yin L, Deng Q, Nguyen T, Hales CM, Wingo T, et al. A multi-network approach identifies protein-specific co-expression in asymptomatic and symptomatic Alzheimer's disease. Cell Syst. 2017;4(60-72):e64. https://doi.org/ 10.1016/j.cels.2016.11.006.

64. Rehrauer H, Opitz L, Tan G, Sieverling L, Schlapbach R. Blind spots of quantitative RNA-seq: the limits for assessing abundance, differential expression, and isoform switching. BMC Bioinform. 2013;14:370.

65. Evans TG. Considerations for the use of transcriptomics in identifying the "genes that matter" for environmental adaptation. J Exp Biol. 2015:218:1925-35.

66. Jung IR, Choi SE, Hong SA, Hwang Y, Kang Y. Sodium fluorocitrate having protective effect on palmitate-induced beta cell death improves hyperglycemia in diabetic db/db mice. Sci Rep. 2017;7:12916.

67. Peterson LJ, Flood PM. Oxidative stress and microglial cells in Parkinson's disease. Mediators Inflamm. 2012;2012:401264.

68. Katoh M, Wu B, Nguyen HB, Thai TQ, Yamasaki R, Lu H, Rietsch AM, Zorlu MM, Shinozaki Y, Saitoh Y, et al. Polymorphic regulation of mitochondrial fission and fusion modifies phenotypes of microglia in neuroinflammation. Sci Rep. 2017;7:4942.

69. Baron R, Babcock AA, Nemirovsky A, Finsen B, Monsonego A. Accelerated microglial pathology is associated with Abeta plaques in mouse models of Alzheimer's disease. Aging Cell. 2014;13:584-95.

70. Heindl S, Gesierich B, Benakis C, Llovera G, Duering M, Liesz A. Automated morphological analysis of microglia after stroke. Front Cell Neurosci. 2018;12:106

71. Dias V, Junn E, Mouradian MM. The role of oxidative stress in Parkinson's disease. J Parkinsons Dis. 2013:3:461-91.

72. Das A, Kim SH, Arifuzzaman S, Yoon T, Chai JC, Lee YS, Park KS, Jung KH, Chai YG. Transcriptome sequencing reveals that LPS-triggered transcriptional responses in established microglia BV2 cell lines are poorly representative of primary microglia. J Neuroinflamm. 2016:13:182.

73. Butovsky O, Jedrychowski MP, Moore CS, Cialic R, Lanser AJ, Gabriely G, Koeglsperger T, Dake B, Wu PM, Doykan CE, et al. Identification of 
a unique TGF-beta-dependent molecular and functional signature in microglia. Nat Neurosci. 2014;17:131-43.

74. Schneider CS, Perez JG, Cheng E, Zhang C, Mastorakos P, Hanes J, Winkles JA, Woodworth GF, Kim AJ. Minimizing the non-specific binding of nanoparticles to the brain enables active targeting of Fn14-positive glioblastoma cells. Biomaterials. 2015;42:42-51.

75. Park KS, Tae J, Choi B, Kim YS, Moon C, Kim SH, Lee HS, Kim J, Park J, Lee $\mathrm{JH}$, et al. Characterization, in vitro cytotoxicity assessment, and in vivo visualization of multimodal, RITC-labeled, silica-coated magnetic nanoparticles for labeling human cord blood-derived mesenchymal stem cells. Nanomed Nanotechnol Biol Med. 2010;6:263-76.

76. Malvindi MA, DeMatteis V, Galeone A, Brunetti V, Anyfantis GC, Athanassiou A, Cingolani R, Pompa PP. Toxicity assessment of silica coated iron oxide nanoparticles and biocompatibility improvement by surface engineering. PLoS ONE. 2014;9:e85835.

77. Sabella S, Carney RP, Brunetti V, Malvindi MA, Al-Juffali N, Vecchio G, Janes SM, Bakr OM, Cingolani R, Stellacci F, Pompa PP. A general mechanism for intracellular toxicity of metal-containing nanoparticles. Nanoscale. 2014;6:7052-61.

78. Lee MJ, Lee SJ, Yun SJ, Jang J-Y, Kang H, Kim K, Choi I-H, Park S. Silver nanoparticles affect glucose metabolism in hepatoma cells through production of reactive oxygen species. Int J Nanomed. 2015;11:5568. https://doi.org/10.2147/IJN.S94907.

79. Wang L, Pavlou S, Du X, Bhuckory M, Xu H, Chen M. Glucose transporter 1 critically controls microglial activation through facilitating glycolysis. Mol Neurodegener. 2019;14:2.

80. D'Ignazio L, Bandarra D, Rocha S. NF-KB and HIF crosstalk in immune responses. FEBS J. 2016;283:413-24.

81. Obaid M, Udden SMN, Alluri P, Mandal SS. LncRNA HOTAIR regulates glucose transporter Glut1 expression and glucose uptake in macrophages during inflammation. Sci Rep. 2021;11:232.

82. Yang T, Yao Q, Cao F, Liu Q, Liu B, Wang X-H. Silver nanoparticles inhibit the function of hypoxia-inducible factor- 1 and target genes: insight into the cytotoxicity and antiangiogenesis. Int J Nanomed. 2016;11:6679-92.

83. Lin Y-F, Chiu IJ, Cheng F-Y, Lee Y-H, Wang Y-J, Hsu Y-H, Chiu H-W. The role of hypoxia-inducible factor-1 a in zinc oxide nanoparticleinduced nephrotoxicity in vitro and in vivo. Part Fibre Toxicol. 2016;13:52.

84. Sharma M, Salisbury RL, Maurer El, Hussain SM, Sulentic CEW. Gold nanoparticles induce transcriptional activity of NF-KB in a B-lymphocyte cell line. Nanoscale. 2013;5:3747-56.

85. Garcia-Campos MA, Espinal-Enriquez J, Hernandez-Lemus E. Pathway analysis: state of the art. Front Physiol. 2015;6:383.

86. Shin TH, Nithiyanandam S, Lee DY, Kwon DH, Hwang JS, Kim SG, Jang YE, Basith S, Park S, Mo J-S, Lee G. Analysis of nanotoxicity with integrated omics and mechanobiology. Nanomaterials. 2021;11:2385.

87. Lee DY, Lee SE, Kwon DH, Nithiyanandam S, Lee MH, Hwang JS, Basith $\mathrm{S}$, Ahn JH, Shin TH, Lee G. Strategies to improve the quality and freshness of human bone marrow-derived mesenchymal stem cells for neurological diseases. Stem Cells Int. 2021;2021:8444599.

88. Subramanian I, Verma S, Kumar S, Jere A, Anamika K. Multi-omics data integration, interpretation, and its application. Bioinform Biol Insights. 2020;14:1177932219899051-1177932219899051.

89. Khatri P, Sirota M, Butte AJ. Ten years of pathway analysis: current approaches and outstanding challenges. PLoS Comput Biol. 2012;8:e1002375

90. Jin L, Zuo XY, Su WY, Zhao XL, Yuan MQ, Han LZ, Zhao X, Chen YD, Rao SQ. Pathway-based analysis tools for complex diseases: a review. Genomics Proteomics Bioinform. 2014;12:210-20.

91. Lee DY, Jin MS, Manavalan B, Kim HK, Song JH, Shin TH, Lee G. Bidirectional transcriptome analysis of rat bone marrow-derived mesenchymal stem cells and activated microglia in an in vitro coculture system. Stem Cells Int. 2018;2018:6126413.

92. Kornfeld OS, Hwang S, Disatnik MH, Chen CH, Qvit N, Mochly-Rosen D. Mitochondrial reactive oxygen species at the heart of the matter: new therapeutic approaches for cardiovascular diseases. Circ Res. 2015:116:1783-99.

93. Chao T, Wang H, Ho PC. Mitochondrial control and guidance of celIular activities of T cells. Front Immunol. 2017;8:473.
94. Jozefczak M, Remans T, Vangronsveld J, Cuypers A. Glutathione is a key player in metal-induced oxidative stress defenses. Int J Mol Sci. 2012:13:3145-75.

95. da Silva AR, Neves J, Mleczko-Sanecka K, Tandon A, Sauer SW, Hentze MW, Muckenthaler MU. Cellular citrate levels establish a regulatory link between energy metabolism and the hepatic iron hormone hepcidin. J Mol Med (Berl). 2017;95:851-60.

96. Welling SH, Hubalek F, Jacobsen J, Brayden DJ, Rahbek UL, Buckley ST. The role of citric acid in oral peptide and protein formulations: relationship between calcium chelation and proteolysis inhibition. Eur J Pharm Biopharm. 2014;86:544-51.

97. Yabuki Y, Fukunaga K. Oral administration of glutathione improves memory deficits following transient brain ischemia by reducing brain oxidative stress. Neuroscience. 2013;250:394-407.

98. Abdel-Salam OME, Youness ER, Mohammed NA, Morsy SMY, Omara EA, Sleem AA. Citric acid effects on brain and liver oxidative stress in lipopolysaccharide-treated mice. J Med Food. 2014;17:588-98.

99. Teeguarden JG, Hinderliter PM, Orr G, Thrall BD, Pounds JG. Particokinetics in vitro: dosimetry considerations for in vitro nanoparticle toxicity assessments. Toxicol Sci. 2007:95:300-12

100. Oberdorster G, Maynard A, Donaldson K, Castranova V, Fitzpatrick J, Ausman K, Carter J, Karn B, Kreyling W, Lai D, et al. Principles for characterizing the potential human health effects from exposure to nanomaterials: elements of a screening strategy. Part Fibre Toxicol. 2005;2:8.

101. Pinto SR, Sarcinelle MA, de Souza Albernaz M, da Silva FMR, Seabra SH, Almeidado Nascimento P, Carvalho CLG, Santos-Oliveira R. In vivo studies: comparing the administration via and the impact on the biodistribution of radiopharmaceuticals. Nucl Med Biol. 2014;41:772-4.

102. Migotto M-a, Bhalla R, Mardon K, Orian J, Weckbecker G, Kneuer R, Reutens $D$. Effect of route of administration on the biodistribution of a novel anti-CD20 antibody in experimental autoimmune encephalomyelitis-variant mice (P2.2-081). Neurology. 2019;92:P2.2-081.

103. Yildirimer L, Thanh NTK, Loizidou M, Seifalian AM. Toxicology and clinical potential of nanoparticles. Nano Today. 2011;6:585-607.

104. Kreyling WG, Hirn S, Schleh C. Nanoparticles in the lung. Nat Biotechnol. 2010;28:1275-6.

105. Akçan R, Aydogan HC, Yildirim MŞ, Taştekin B, Sağlam N. Nanotoxicity: a challenge for future medicine. Turk J Med Sci. 2020;50:1180-96.

106. Ceña V, Játiva P. Nanoparticle crossing of blood-brain barrier: a road to new therapeutic approaches to central nervous system diseases. Nanomedicine. 2018;13:1513-6.

107. Vega RA, Zhang Y, Curley C, Price RL, Abounader R. 370 magnetic resonance-guided focused ultrasound delivery of polymeric brainpenetrating nanoparticle microRNA conjugates in glioblastoma. Neurosurgery. 2016;63:210-210.

108. Liu D-Z, Cheng Y, Cai R-Q, Wang BDW-W, Cui H, Liu M, Zhang B-L, Mei Q-B, Zhou S-Y. The enhancement of siPLK1 penetration across BBB and its anti glioblastoma activity in vivo by magnet and transferrin co-modified nanoparticle. Nanomed Nanotechnol Biol Med. 2018;14:991-1003.

109. Behzadi S, Serpooshan V, Tao W, Hamaly MA, Alkawareek MY, Dreaden EC, Brown D, Alkilany AM, Farokhzad OC, Mahmoudi M. Cellular uptake of nanoparticles: journey inside the cell. Chem Soc Rev. 2017:46:4218-44.

110. Dos Reis SRR, Pinto SR, de Menezes FD, Martinez-Manez R, Ricci-Junior E, Alencar LMR, Helal-Neto E, da Silva de Barros AO, Lisboa PC, SantosOliveira R. Senescence and the impact on biodistribution of different nanosystems: the discrepancy on tissue deposition of graphene quantum dots, polycaprolactone nanoparticle and magnetic mesoporous silica nanoparticles in young and elder animals. Pharm Res. 2020;37:40.

111. Liao WY, Li HJ, Chang MY, Tang AC, Hoffman AS, Hsieh PC. Comprehensive characterizations of nanoparticle biodistribution following systemic injection in mice. Nanoscale. 2013;5:11079-86.

112. Cross B. The biology and medicine of rabbits and rodents, 4th edn. Can Vet J. 1996:37:759-60

113. Turner PV, Brabb T, Pekow C, Vasbinder MA. Administration of substances to laboratory animals: routes of administration and factors to consider. J Am Assoc Lab Anim Sci. 2011;50:600-13.

114. Pinkernelle J, Calatayud P, Goya GF, Fansa H, Keilhoff G. Magnetic nanoparticles in primary neural cell cultures are mainly taken up by microglia. BMC Neurosci. 2012;13:32. 
115. Jiang $Y$, Lin $X$, Tang $Z$, Lee $C$, Tian G, Du Y, Yin $X$, Ren $X$, Huang $L$, Ye Z, et al. Critical role of caveolin-1 in ocular neovascularization and multitargeted antiangiogenic effects of cavtratin via JNK. Proc Natl Acad Sci U S A. 2017;114:10737-42.

116. Minami SS, Sun B, Popat K, Kauppinen T, Pleiss M, Zhou Y, Ward ME, Floreancig P, Mucke L, Desai T, Gan L. Selective targeting of microglia by quantum dots. J Neuroinflamm. 2012;9:22.

117. Chen C, Li HQ, Liu YJ, Guo ZF, Wu HJ, Li X, Lou HF, Zhu L, Wang D, Li $X M$, et al. A novel size-based sorting mechanism of pinocytic luminal cargoes in microglia. J Neurosci. 2015;35:2674-88.

118. Galloway DA, Phillips AEM, Owen DRJ, Moore CS. Phagocytosis in the brain: homeostasis and disease. Front Immunol. 2019;10:790.

119. Limbach LK, Li Y, Grass RN, Brunner TJ, Hintermann MA, Muller M, Gunther D, Stark WJ. Oxide nanoparticle uptake in human lung fibroblasts: effects of particle size, agglomeration, and diffusion at low concentrations. Environ Sci Technol. 2005;39:9370-6.

120. Foroozandeh P, Aziz AA. Insight into cellular uptake and intracellular trafficking of nanoparticles. Nanoscale Res Lett. 2018;13:339.

121. Rennick JJ, Johnston APR, Parton RG. Key principles and methods for studying the endocytosis of biological and nanoparticle therapeutics. Nat Nanotechnol. 2021;16:266-76.

122. Phagocytosis GS. An immunobiologic process. Immunity. 2016:44:463-75

123. Xu Y, Xia J, Liu S, Stein S, Ramon C, Xi H, Wang L, Xiong X, Zhang L, He D, et al. Endocytosis and membrane receptor internalization: implication of F-BAR protein Carom. Front Biosci (Landmark Ed). 2017;22:1439-57.

124. Janda E, Boi L, Carta AR. Microglial phagocytosis and its regulation: a therapeutic target in Parkinson's disease? Front Mol Neurosci. 2018;11:144.

\section{Publisher's note}

Springer Nature remains neutral with regard to jurisdictional claims in published maps and institutional affiliations.

- fast, convenient online submission

- thorough peer review by experienced researchers in your field

- rapid publication on acceptance

- support for research data, including large and complex data types

- gold Open Access which fosters wider collaboration and increased citations

- maximum visibility for your research: over $100 \mathrm{M}$ website views per year

At BMC, research is always in progress.

Learn more biomedcentral.com/submissions 